\title{
LASER INDUCED-BREAKDOWN SPECTROSCOPY (LIBS): HISTÓRICO, FUNDAMENTOS, APLICAÇÕES E POTENCIALIDADES
}

Vinicius C. Costa ${ }^{\mathrm{a}}$, Amanda S. Augusto ${ }^{\mathrm{a}}$, Jeyne P. Castro ${ }^{\mathrm{a}}$, Raquel C. Machado ${ }^{\mathrm{a}}$, Daniel F. Andrade ${ }^{\mathrm{a}}$, Diego V. Babos ${ }^{\mathrm{a}}$, Marco A. Sperança ${ }^{a}$, Raimundo R. Gamela ${ }^{a}$ e Edenir R. Pereira-Filho*,a, ${ }^{*}$

Departamento de Química, Universidade Federal de São Carlos, 13565-905 São Carlos - SP, Brasil

Recebido em 08/10/2018; aceito em 17/01/2019; publicado na web em 11/03/2019

LASER INDUCED-BREAKDOWN SPECTROSCOPY (LIBS): HISTORY, FUNDAMENTALS, APPLICATIONS AND POTENTIALITIES. This review attempts to present a broad view of the technique laser-induced breakdown spectroscopy (LIBS), since its origin, fundamentals, sample preparation strategies, use of chemometric tools for data processing, the advantages and limitations with regard to qualitative and quantitative analysis, aplications and future trends as an analytical technique that is in consolidation in analytical chemistry. LIBS is a rapid and versatile, which is able of providing qualitative and quantitative analytical information for practically any sample, in a virtually non-destructive way, without any substantial sample preparation. The instrumentation is simple, robust, compact, and enables remote analysis. The advancement of the LIBS applications in the areas of agriculture, environmental, food, biological/pharmaceutical, forensic, metallurgy and electronic waste were discussed in detail in this review. We consider that this review will be an important tool concerning dissemination of the LIBS, mainly for audience of undergraduate courses, and disciplines related to instrumental analysis.

Keywords: LIBS; direct analysis; qualitative and quantitative analysis.

\section{INTRODUÇÃO}

A Química Analítica tem mostrado, nas últimas 5 décadas, uma grande capacidade de desenvolvimento e apresentação de respostas para diversos questionamentos da humanidade. ${ }^{1,2}$ Essas questões envolvem aspectos de saúde pública, ambientais e econômicos. Em 2017, as 20 maiores empresas fabricantes de equipamentos analíticos comercializaram 26 bilhões de dólares americanos. ${ }^{3}$ Esses números atestam o aspecto estratégico da química analítica, em que a obtenção de dados precisos e exatos transcendem a bancada do laboratório e têm peso considerável na tomada de decisões econômicas e sociais. Somente no Brasil, a área de química analítica representa cerca de $3 \%$ das publicações mundiais em revistas científicas representativas da área. ${ }^{4}$

Dessa forma, é recorrente a apresentação de técnicas analíticas cada vez mais sensíveis e voltadas para o equacionamento de questões essenciais do nosso dia a dia. Nesse sentido, a espectrometria de emissão óptica com plasma induzido por laser (laser-induced breakdown spectroscopy, LIBS) reflete grande parte desse desenvolvimento, pois unifica alguns aspectos desejados por todo profissional da área de química analítica: simplicidade, elevada frequência analítica, caráter multielementar, reduzida manipulação das amostras e obtenção de dados precisos e exatos. Além disso, apresenta praticamente caráter não-destrutivo, porque somente uma porção muito pequena da amostra sofre o processo de ablação (cerca de nanogramas a microgramas). ${ }^{5}$

Todas essas vantagens somadas com a simplicidade da instrumentação fazem com que a LIBS seja uma das técnicas mais versáteis já desenvolvidas. O crescente interesse pelo uso da LIBS pode ser visto através do número de trabalhos que vêm sendo publicados ao longo dos últimos 30 anos, como mostrado na Figura 1. De acordo com a base de dados da Web of Science, durante esse período cerca de 4500 trabalhos foram publicados e os últimos 11 anos (2008-2018) respondem por cerca de $78 \%$ do total das publicações. Esses dados exemplificam a "onda" de interesse pela LIBS, sendo possível

*e-mail: erpf@ufscar.br encontrar atualmente uma ampla variedade de trabalhos propondo inovações e melhorias. Assim, o objetivo dessa revisão é apresentar ao leitor uma visão geral sobre a LIBS, com discussões relacionadas com (i) panorama histórico; (ii) o estado da arte; (iii) as estratégias de preparo de amostras; (iv) o uso da quimiometria no tratamento de dados; (v) as vantagens e limitações no que diz respeito a análises qualitativas e quantitativas; (vi) e as suas aplicações em diversos campos de atuação, desde aqueles relacionados com agricultura até aquelas de caráter tecnológico.

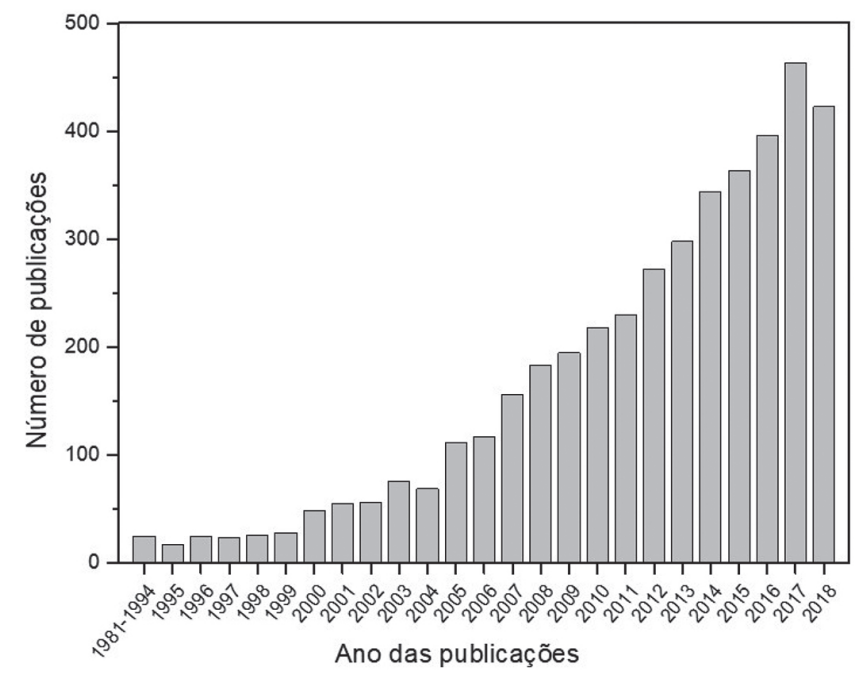

Figura 1. Número de publicações envolvendo LIBS

\section{LIBS: O INÍCIO}

Os fundamentos da técnica LIBS deram-se no início do século XX, quando Albert Einstein lançou, em 1917, os fundamentos teóricos sobre a emissão estimulada. ${ }^{6}$ Em 1958, Charles Townes e seu colaborador Arthur Schawlow discutiram algumas possibilidades de 
criar o que eles chamaram de microwave amplification by stimulated emission of radiation (MASER), em um artigo que se tornou clássico na física de lasers e é considerado o marco para o desenvolvimento do primeiro laser?

Contudo, foi somente em 1960 que o engenheiro norte americano Theodore Maiman produziu o primeiro dispositivo de laser com uma montagem simples, feito de um bastão de rubi colocado no centro de uma lâmpada de flash. Ambos os lados do bastão foram cobertos cuidadosamente com camadas de prata, no qual um dos lados era semi-transparente, permitindo a passagem da radiação. ${ }^{8} \mathrm{Um}$ ano depois, em 1961, Javan et al. ${ }^{9}$ desenvolveram o primeiro laser a gás, constituído por uma mistura de hélio e neônio a baixa pressão. No mesmo período foram desenvolvidos diversos lasers de estado sólido, como o $\mathrm{Y}_{3} \mathrm{Al}_{5} \mathrm{O}_{12}$ (YAlG), $\mathrm{Y}_{3} \mathrm{Ga}_{5} \mathrm{O}_{12}$ (YGaG), $\mathrm{Gd}_{3} \mathrm{Ga}_{5} \mathrm{O}_{12}(\mathrm{GdGaG})$ com propriedades desejáveis no material receptor do laser. No entanto, a configuração que resultou os melhores resultados foi aquela dopada com íon neodímio $\left(\mathrm{Nd}^{3+}\right)$ em seu interior, imerso em uma solução de granada de ítrio-alumínio ( $\mathrm{YAG}, \mathrm{Y}_{3} \mathrm{Al}_{5} \mathrm{O}_{12}$ ) conhecido por $\mathrm{Nd}$ :YAG. ${ }^{10}$ Esse tipo de configuração apresenta características que os diferenciam das demais, pois são estáveis, resistentes, opticamente isotrópicos e com menor oscilação do laser. O laser de Nd:YAG evoluiu e vem sendo amplamente usado para iniciar o plasma.

Apesar do uso de lasers nos anos 1960, estes ainda não eram utilizados como fontes de ablação. Dois anos depois de Maiman demonstrar o funcionamento do laser de rubi, esse mesmo laser foi utilizado por Brech e Cross ${ }^{11}$ para produzir vapores na superfície de materiais metálicos e não metálicos. Esses vapores eram excitados por uma fonte de energia auxiliar a fim de formar um microplasma com objetivo de detectar o espectro de emissão. Em 1963, Debras-Guedon e Liodec ${ }^{12}$ publicaram o primeiro uso analítico de laser para análise espectrofotométrica de superfícies. Já Maker et al. ${ }^{13}$ mencionaram a primeira observação de ablação induzida opticamente em um gás, e Runge et al. ${ }^{14}$ relataram o uso de um laser de rubi para produzir a excitação direta de centelhas nos metais. Apenas em 1965, o primeiro modelo de laser induzido por gás foi proposto por Zel'dovich e Raizer. ${ }^{15}$

Entre os anos de 1964 e 1967, foram fabricados os primeiros instrumentos comerciais por Jarrell-Ash (Estados Unidos da América) e Carl Zeiss (Alemanha). Estes instrumentos empregavam a energia do pulso do laser apenas para ablação enquanto a excitação era feita por um arco elétrico. No entanto, estes equipamentos tiveram pouco tempo de utilização, pois apresentavam baixa precisão e exatidão quando comparados com a espectroscopia de centelha convencional que apresentava temperatura suficiente para causar a emissão de muitos elementos da tabela periódica, permitindo análises semi-quantitativas e qualitativas. ${ }^{16}$

Desde o desenvolvimento da LIBS, diversas pesquisas foram realizadas a fim de melhorar o desempenho da técnica. Em 1966, Young et al..$^{17}$ descreveram as características de centelha de ar induzido por laser. No início dos anos 70, após quase 10 anos de estudos acerca dos fenômenos físicos envolvidos na formação de plasmas induzidos por laser, os primeiros equipamentos comerciais explorando a técnica LIBS foram disponibilizados no mercado pelas empresas Jarrell-Ash Corporation e VEB Carl Zeiss. Após uma fase inicial de euforia, o interesse pela técnica LIBS entrou em declínio devido ao alto custo da instrumentação e baixíssimo desempenho analítico, em comparação às técnicas convencionais de espectrometria atômica. Durante os anos de 1960 e 1980, parte das pesquisas sobre plasmas e lasers e suas aplicações tiveram origem na Rússia e posteriormente foram abordadas em um livro clássico de Raizer, "Laser-induced Discharge Phenomena", publicado em inglês em 1977.7

No início dos anos 1980, o interesse pela utilização da LIBS renasceu com o desenvolvimento de lasers mais compactos, robustos e de menor custo, bem como detectores mais sensíveis, com melhor resolução espectral e temporal, e melhor discriminação entre o espectro de emissão e o de fundo causado pelo continuum de emissão do plasma. O avanço tecnológico nos componentes ópticos e eletrônicos possibilitou o desenvolvimento e miniaturização de diferentes tipos de lasers, surgindo a possibilidade da aplicação em análises diretas em praticamente qualquer tipo de amostras. Ademais, com o seu renovado caráter de portabilidade, possibilitou o desenvolvimento de procedimentos de análises in situ. Assim, o interesse na utilização desta técnica tem aumentado com grandes avanços e potencialidades para análise de amostras sólidas..$^{718-20}$ Além disso, a possibilidade de acoplamento com outras técnicas analíticas também contribui para despertar o interesse pelos processos de ablação por laser. A ablação por laser como uma técnica de amostragem acoplada a técnicas analíticas estabelecidas, tais como espectrometria de emissão óptica com plasma indutivamente acoplado (ICP OES) ${ }^{21}$ e espectrometria de massas com plasma indutivamente acoplado (ICP-MS), ${ }^{22}$ aprimorou a capacidade analítica para análise de amostras sólidas, minimizando o tempo de análise, reduzindo a exposição a produtos químicos perigosos e resíduos, e tornou-se uma alternativa aos métodos de digestão ácida para análise química. Além disso, sistemas laser ablation (LA)-LIBS têm sido recentemente desenvolvidos, permitem novas possibilidades de medição e realizam análises por LIBS enquanto simultaneamente transportam partículas abladas para um instrumento ICP-MS, por exemplo. ${ }^{23,24}$

\section{FUNDAMENTOS DA LIBS}

\section{Instrumentação}

A LIBS baseia-se na espectrometria de emissão óptica e consiste em uma fonte de laser que, com o auxílio de lentes focalizadoras, emite pulsos de alta energia diretamente na amostra. Essa amostra pode ser sólida, líquida ou gasosa. Após a incidência do pulso de laser, que pode apresentar uma duração de nano, pico ou femto segundos, a amostra passa pelos processos de aquecimento, derretimento (amostras sólidas) e vaporização em um curto intervalo de tempo. A energia do pulso de laser produz um plasma em altas temperaturas (da ordem de 10.000-20.000 K). O material vaporizado (átomos, íons e moléculas) é excitado para um nível de maior energia e ao retornar ao de menor energia (emissão espontânea), emite radiação específica em comprimento de onda para cada elemento. ${ }^{25-27}$

A Figura 2 apresenta um esquema típico de um sistema LIBS, no qual os principais componentes são: (1) fonte de energia; (2) lentes para focalizar o pulso de laser na superfície da amostra; (3) suporte da amostra que pode ser montada em uma câmara de ablação; (4) fibra óptica responsável pela coleta da radiação oriunda do plasma; (5) sistema de detecção (espectrômetro/detector) e (6) computador para controle preciso dos eventos temporais, como: disparo do pulso do laser e registro do espectro.

Os componentes básicos do sistema LIBS são similares para as diferentes instrumentações existentes, no entanto, a configuração do sistema pode mudar conforme a aplicação desejada. Nestes casos, podem ser adaptados diferentes tipos de laser (ou diferentes comprimentos de onda), detectores, espectrômetros e arranjos ópticos. As diferentes configurações podem conferir a LIBS características diversas, como potência do pulso do laser, sensibilidade, peso, tamanho e portabilidade. Exemplos e detalhes sobre as diferentes configurações de cada componente serão abordados nos tópicos a seguir. ${ }^{26,27}$

\section{Fontes de laser}

A fonte de laser é responsável por todos os processos de absorção, emissão espontânea e emissão estimulada, necessários para que 


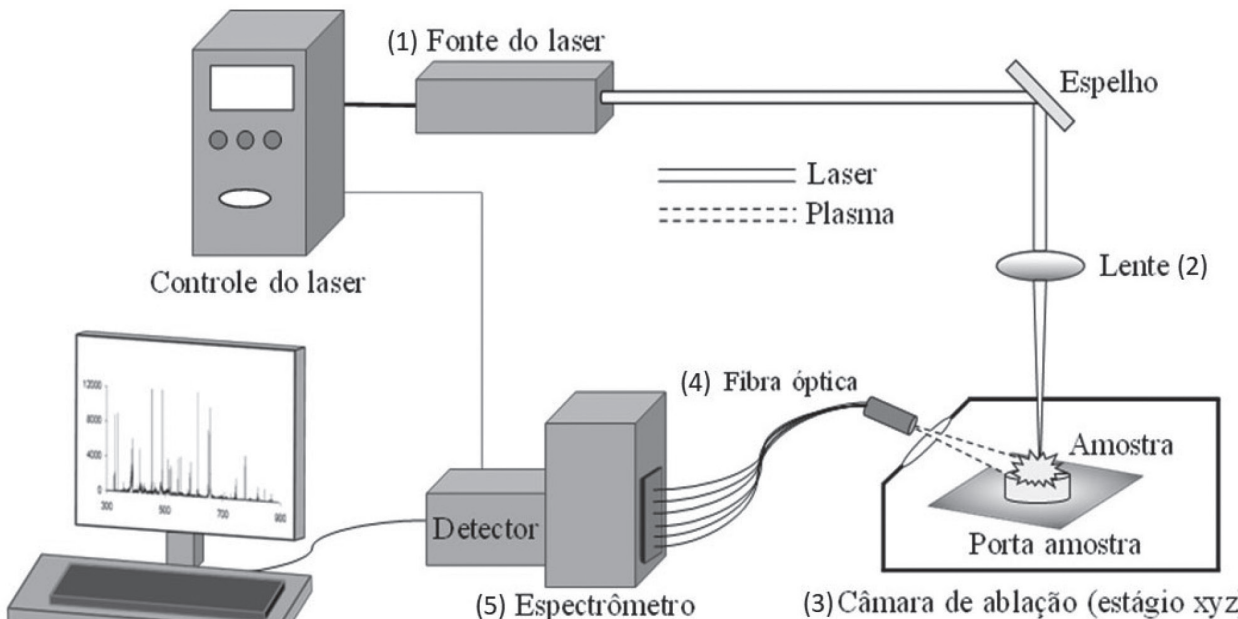

(6) Computador

(5) Espectrômetro

(3) Câmara de ablação (estágio xyz)

Figura 2. Configuração instrumental típica de um equipamento LIBS

ocorra a produção do feixe de laser. A radiação laser é gerada por decaimento energético de uma espécie excitada e emitida por um processo chamado light amplification by stimulated emission of radiation (LASER). Devido ao processo de emissão estimulada, fótons duplicados são produzidos e dessa forma a radiação laser apresenta características como: alta intensidade, direcionalidade, monocromatissidade e coerência. ${ }^{28}$ Esses sistemas são compostos basicamente por três componentes: meio ativo, dispositivo para bombeamento de energia e um ressonador óptico (arranjo de espelhos que fornece a amplificação da luz do laser). O meio ativo é onde ocorrerá todo o processo de inversão populacional, parte da energia recebida será absorvida por íons dopados no material de laser, tais como íons de $\mathrm{Nd}^{3+}$ em um cristal de YAG (granada de alumínio e ítrio). O sistema de bombeamento de energia (Ex., flashlamps, descarga de gás ou outros lasers) é responsável por fornecer energia para o meio ativo e dar início ao processo de inversão da população, ou seja, mais elétrons no estado excitado do que no fundamental. ${ }^{26,27}$

O meio ativo pode ser constituído de uma variedade de materiais que conferem os diferentes tipos de lasers existentes:

- Sólido: rubi, Nd:YAG, Ti:Safira;

- Líquido: corantes orgânicos (Ex., anelinas, rodaminas, cumarinas);

- Gasoso: excímeros (dímeros excitados, tais como $\mathrm{ArF}, \mathrm{XeCl}$ e

$\mathrm{XeF})$, gases nobres $\left(E x, \mathrm{Ag}^{+}, \mathrm{Kr}^{+}\right.$e $\left.\mathrm{He}-\mathrm{Ne}\right)$ e gases moleculares (Ex., $\mathrm{N}_{2}$ e $\mathrm{CO}_{2}$ ).

O comprimento de onda do laser depende do meio ativo e das transições de níveis de energia do meio ativo. É possível gerar pulsos de laser de curta duração com comprimentos de onda variando do ultravioleta ao infravermelho, podendo chegar à ordem de milhões de Watts de potência. ${ }^{26,27}$ Dentre os tipos de laser citados anteriormente, os lasers de Nd:YAG (1064 nm) são os mais utilizados nas aplicações em LIBS, principalmente porque fornecem uma fonte de pulsos de laser de alta densidade e potência focalizada, confiável, compacta e de fácil operação. ${ }^{29}$

Existem três tipos de regimes de duração do laser: nano, pico e femto segundos. Os sistemas de lasers de nano segundos são produzidos através da excitação de um meio ativo, por exemplo, Nd:YAG. O mesmo processo de excitação ocorre para os sistemas de lasers de pico e femto segundos, porém nesses casos a adição de um sistema de amplificação é utilizado, e o mais comumente aplicado é o chirped pulse amplification (CPA) ${ }^{30} \mathrm{O}$ grande diferencial desses três tipos de lasers é em relação ao processo de ablação. A duração do pulso (características temporais do laser) influencia na interação do feixe de laser com o objeto analisado. ${ }^{26-29}$ Essas diferenças são notadamente encontradas quando se trata de processos de ablação de sólidos. Durante a interação do laser com a amostra, ocorre a absorção da energia incidente do laser através do mecanismo de inversão Bremsstrahlung, envolvendo os fótons que são emitidos por elétrons acelerados ou desacelerados em colisões. ${ }^{25,31}$ Essa energia absorvida envolve a termalização dentro do subsistema de elétrons, transferência de energia para o meio e perda de energia devido ao transporte de calor de elétrons para o alvo (amostra).

Em um laser de femto segundos, o tempo de duração do pulso é menor que o tempo de resfriamento de elétrons, nesse caso o processo de ablação pode ser considerado como uma transição direta do sólido para o plasma. Durante esse processo, a condução térmica pode ser negligenciada fazendo com que esse tipo de pulso de laser permita uma alta precisão e processo de ablação livre de recombinação entre os analitos ablados. No laser de pico segundos, ocorre a condução de calor por elétrons e a formação de uma zona de amostra "derretida" ao redor do ponto ablado, fazendo com que a precisão desse processo seja menor. Para os lasers de nano segundos, a longa duração faz com que ocorra a criação de uma grande porção de material "derretido". Nesse caso, parte da evaporação e formação do plasma acaba sendo referente a esse material, reduzindo consideravelmente a precisão. Resumidamente, três características definem os regimes de duração do laser: tempo de resfriamento dos elétrons, de aquecimento do meio e duração do pulso de laser. ${ }^{32-34} \mathrm{O}$ melhor sistema e regime de duração do laser deve ser avaliado e escolhido de acordo com a aplicação desejada pelo analista.

\section{Componentes ópticos}

Além do laser, como fonte de energia para ablação/excitação, e do sistema de difração dos comprimentos de onda e detecção do plasma emitido, os componentes ópticos também são necessários principalmente para focalizar o pulso de laser, coletar e conduzir a radiação do plasma através de um cabo de fibra óptica até o espectrômetro e posteriormente ao detector. ${ }^{26}$

Em LIBS, o feixe de laser pode ser focalizado utilizando lentes ou espelhos que ajudam no direcionamento até a superfície da amostra. A configuração mais simples e comum é a amostra posicionada perpendicularmente à fonte do laser, $^{25}$ e os ajustes do sistema óptico auxiliam desde a focalização do laser, aquisição da radiação do plasma, até os dispositivos de seleção de comprimentos de onda (Figura 2). Os sistemas mais sofisticados empregam múltiplas lentes, combinadas 
a espelhos e fibra óptica, em situações que requerem excelente foco, focalização do laser a longa distância, ou menor diâmetro do pulso de laser (maior densidade eletrônica por pulso). ${ }^{27}$

Existe uma ampla variedade de tipos de lentes, no entanto, todas podem ser incluídas em duas classes gerais de acordo com o efeito que causam em um feixe de luz paralelo: (1) lentes convergentes (ou positivas, convexas) e (2) divergentes (ou negativas, côncavas). As lentes possuem diferentes parâmetros que são relevantes, tais como distância focal, diâmetro e o material. A distância focal é o parâmetro mais importante na descrição de uma lente, isto é, a distância do ponto focal no qual os raios de luz estão paralelos e passam através de um lado da lente até o ponto onde são reunidos no outro lado da lente. ${ }^{35}$ Para análises in situ, as lentes tipicamente utilizadas possuem distâncias focais de 50 a $150 \mathrm{~mm}$ e diâmetros que variam entre 25 a 50 $\mathrm{mm}$. O material da lente depende do comprimento de onda do laser. Para comprimentos de onda na região do visível ao infravermelho próximo, são utilizadas lentes de vidro borossilicato (BK7); em regiões do espectro abaixo de $340 \mathrm{~nm}$ as lentes de quartzo são as mais indicadas; para comprimentos de onda na região do infravermelho distante, os materiais empregados são o seleneto de zinco, germânio e cloreto de sódio. ${ }^{26,28,35}$

Os cabos de fibra óptica são utilizados para facilitar a coleta da radiação do plasma quando o sistema de detecção não pode ser posicionado próximo à amostra. Quando a LIBS é empregada para a análise em ambientes perigosos ou "agressivos", geralmente o espectrômetro é posicionado a alguns metros de distância do objeto de medida. O uso da fibra óptica como um guia óptico da luz do plasma até o espectrômetro permite a análise de objetos em altas temperaturas. Essa é uma vantagem significativa e de especial interesse na metalurgia em ambiente industrial para análise de ligas metálicas em altas temperaturas no processo de produção. ${ }^{30}$ Para usar a fibra óptica é preciso ter uma lente focalizando a luz até o cabo de coleta ou diretamente posicionada e apontada para a superfície da amostra. A combinação da lente e fibra óptica aumenta a sensibilidade da coleta da radiação ao alinhamento do sistema óptico. ${ }^{26,28,35}$

\section{Sistema de detecção}

O sistema de detecção espectral é responsável por coletar, resolver e medir a emissão atômica do plasma formado na amostra. Usualmente, o sistema de detecção consiste no seletor de comprimento de onda (monocromador ou uma grade de difração) e um detector óptico. Devido à alta complexidade dos espectros obtidos por LIBS, em que são obtidas uma infinidade de múltiplas linhas de emissão muito próximas umas das outras, o sistema de detecção deve conter um espectrômetro associado a um detector apropriado que forneça uma medida rápida em um baixo tempo de aquisição de dados. ${ }^{28}$

$\mathrm{O}$ espectrômetro é um compartimento onde se encontram os componentes ópticos, tais como janela de entrada da radiação, espelhos, redes de difração e janela de saída. O espectrômetro dispersa a radiação emitida do plasma induzido pelo laser para obter o espectro em termos de intensidade em função do comprimento de onda. Esse sistema deve ter a capacidade de cobrir a maior extensão de comprimentos de onda simultaneamente e, ao mesmo tempo, ter uma alta resolução espectral $(0,003-0,1 \mathrm{~nm})$ para evitar interferências. ${ }^{28,30}$

Para isso, diferentes formas de montagem têm sido desenvolvidas e empregadas, e os espectrômetros mais comuns são: (a) CzernyTurner, (b) Paschen-Runge e (c) echelle. ${ }^{26,36}$ Em LIBS, a tecnologia echelle é a mais utilizada desde o final dos anos 1990, quando as primeiras aplicações foram reportadas. ${ }^{37,38}$ Esse sistema é compacto, abrange uma ampla faixa de comprimentos de onda (a partir de 200 a $1000 \mathrm{~nm})$ e possui alta resolução espectral $(\lambda / \Delta \lambda$ até maior que $10.000) .^{28}$
Os detectores são dispositivos que convertem o sinal óptico gerado pelo espectrômetro em um sinal elétrico, que possa ser registrado e processado pelo computador. O detector deve ter uma alta eficiência de detecção com um máximo de sensibilidade para todo o espectro obtido. Vários tipos de detectores são utilizados para registrar a radiação espectral dispersada. Dentre os mais usados estão os tubos fotomultiplicadores (PMT, photomultiplier tube), matriz de fotodiodos (PDA, photodiode array), intensified PDA (IPDA), charge-coupled device (CCD) e intensified CCD (ICCD). ${ }^{28}$

Quando um CCD ou ICCD é acoplado a espectrômetros echelle, um sistema de detecção robusto para medir linhas de emissão em LIBS é montado. Essa configuração tem sido muito empregada e permite a cobertura de uma ampla faixa espectral $(165$ a $1000 \mathrm{~nm})$, alta resolução que permite evitar interferências espectrais em matrizes complexas e análises multielementares com alta sensibilidade. A combinação de um espectrômetro Paschen-Runge com tubos fotomultiplicadores pode ser uma alternativa menos dispendiosa aos sistemas convencionais ou sistemas de espectrômetros echelle acoplados a um ICCD. Para análises com ambos os sistemas, os espectrômetros Paschen-Runge/PMT e echelle/ICCD mostram desempenhos semelhantes em termos de limite de detecção (LOD) e análise multielementar de um pequeno número de elementos $(<10)$. A escolha da configuração óptica ideal para LIBS dependerá de vários fatores incluindo o número de elementos e comprimentos de onda a serem monitorados, a faixa de concentração dos analitos e a sensibilidade desejada. ${ }^{26,28,36}$

\section{PREPARO DE AMOSTRAS}

Uma das características mais atrativas da LIBS é a possibilidade da análise direta com o mínimo ou nenhum preparo de amostras..$^{39,40}$ Apesar da possibilidade de análise de amostras nas formas líquida e gasosa, é na forma sólida que majoritariamente as amostras são analisadas. Neste tópico, apresentaremos as principais estratégias de preparo para amostras sólida, líquida e gasosa.

Comumente, as amostras sólidas podem ser analisas de forma direta, tanto in natura ${ }^{41}$ como na forma de pastilhas preparadas a partir do material moído e/ou triturado. ${ }^{40}$ Para amostras sólidas que apresentam homogeneidade apropriada, é possível dispensar a etapa de preparo, como é o caso de amostras de vidro, ${ }^{42}$ ligas metálicas, ${ }^{43}$ polímeros, ${ }^{44}$ fósseis ${ }^{45}$ e ligas ortopédicas. ${ }^{46}$ Cabe informar que a homogeneidade das amostras referidas são provenientes da constituição original das mesmas, e por isso a etapa de preparo é dispensada.

Para amostras sólidas heterogêneas, recomenda-se uma etapa de moagem a fim de diminuir o tamanho de partículas. Essa etapa é importante, visto que tem como objetivo reduzir a heterogeneidade das amostras, proporcionando a análise das mesmas com alta reprodutibilidade. Após essa etapa, agora com as amostras homogêneas na forma de pó, recomenda-se a prensagem das mesmas para obtenção de pastilhas..$^{40} \mathrm{Em}$ relação à massa da amostra usada para o preparo das pastilhas, fatores como o diâmetro, espessura requerida e a densidade do material devem ser avaliados. Por exemplo, para pastilhas de suplemento mineral para bovinos, com $12 \mathrm{~mm}$ de diâmetro e 3 mm de espessura são necessárias $500 \mathrm{mg}$ de amostra. ${ }^{47}$

No preparo das pastilhas, deve-se certificar que as mesmas sejam coesas e resistentes para suportar a onda de choque formada durante a expansão do plasma induzido por laser. A coesão e resistência das pastilhas estão diretamente ligadas à distribuição do tamanho das partículas. No caso de pastilhas de amostras vegetais, recomenda-se que as partículas sejam menores que $100 \mu \mathrm{m}$. De forma geral, as pastilhas preparadas com partículas menores são mais resistentes, e isso reflete diretamente na precisão das medidas, pois quanto mais compacta e mecanicamente resistente, mais reprodutível será a interação 
entre o laser e a amostra. ${ }^{40}$ Nessa perspectiva, Costa et al. ${ }^{48}$ usaram a estratégia referida em amostras de moluscos bivalves liofilizadas e posteriormente moídas para diminuição do tamanho das partículas. A massa de amostra usada pelos autores foi relativamente pequena (250 mg), e as pastilhas apresentaram boa resistência mecânica, não apresentando sinais de fratura ao redor da cratera. Nesse trabalho, foi aplicada uma energia do pulso de laser de $40 \mathrm{~mJ}$ e a área do pulso de $50 \mu \mathrm{m}$, resultando em uma fluência de $2037 \mathrm{~J} \mathrm{~cm}^{-2}$ com um laser de Nd:YAG de $1064 \mathrm{~nm}$.

Apesar da estratégia do uso de pastilhas ser muito simples, em alguns casos, não é possível produzir pastilhas para algumas amostras que estejam na forma de pó. Assim, recomenda-se utilizar um material aglutinante (binder) para minimizar as diferenças na porosidade, garantindo maior resistência e eficiência na interação laser-amostra. ${ }^{40}$ Alguns tipos de aglutinantes têm sido utilizados para o preparo de pastilhas, por exemplo, celulose microcristalina, ${ }^{49}$ ácido bórico, ${ }^{50} \mathrm{e} \mathrm{KBr}^{51}$ A proporção em massa de aglutinante/amostra no preparo das pastilhas pode variar entre 10 e 50\%, e essa variação depende de fatores como propriedades da amostra e da resistência mecânica das pastilhas. ${ }^{40}$ No trabalho proposto por Peruchi et al.$^{52}$ os autores analisaram farinha de trigo, no entanto, as pastilhas não apresentavam boa coesão, sendo necessário o uso de um aglutinante. Os autores testaram três tipos de aglutinantes em três diferentes proporções, e os melhores resultados foram obtidos com $30 \% \mathrm{~m} \mathrm{~m}^{-1}$ de celulose. Em alguns casos, materiais utilizados como aglutinantes (Ex., celulose), podem ter outra finalidade. Nesse sentido, Augusto et $a l .{ }^{49}$ propuseram um preparo de amostras de leite em pó utilizando celulose microcristalina como branco analítico. Além disso, foram preparadas misturas celulose-leite em diferentes proporções. Essas misturas foram pastilhadas e analisadas diretamente por LIBS

Uma das desvantagens do uso de pastilhas em análise por LIBS é que não é possível realizar um mapeamento químico ao longo de uma amostra, pois, nesse caso, a distribuição original dos elementos não é mais a mesma. O objetivo do mapeamento químico geralmente é identificar a posição original dos elementos estudados ao longo de uma amostra, sem nenhum preparo; dessa forma, qualquer preparo, como a moagem e posterior adição de aglutinante para formação de pastilhas, não preservará as informações originais da composição e localização dos elementos na amostra. ${ }^{45,53}$

Outra estratégia de preparo de amostras sólidas é a transferência de uma pequena quantidade da amostra em pó para uma fita adesiva. Essa estratégia é recomendada quando a quantidade de amostra não é suficiente para a confecção da pastilha. Usando esse procedimento, Silva et al.$^{54}$ desenvolveram um método rápido para identificação de resíduos de disparo de arma de fogo, compostos por $\mathrm{Pb}$ proveniente do iniciador, Ba proveniente do oxidante e Sb proveniente do combustível. Diversos voluntários foram selecionados para efetuarem disparos. Após esse processo, os autores coletaram o material com fita adesiva na mão dos voluntários. As fitas adesivas contendo as partículas provenientes dos disparos foram levadas diretamente para análise em LIBS. A partir dos elementos característicos da pólvora, foram propostos modelos de classificação usando o soft independent modeling of class analogies (SIMCA), para a identificação de suspeitos de disparo com armas de fogo.

Para o preparo de amostras líquidas, alguns problemas adicionais podem surgir. ${ }^{55} \mathrm{~A}$ interação laser-amostra é afetada, pois parte da energia do laser é dissipada, espalhando a amostra (splashing). Em consequência, a reprodutibilidade e repetibilidade das análises são drasticamente deterioradas. Além disso, a temperatura do plasma é comprometida (menor temperatura), dificultando a excitação/atomização das espécies presentes na amostra. A fim de contornar essas características indesejáveis, algumas estratégias de preparo têm sido propostas e geralmente envolvem a transformação da matriz líquida em um sólido. As estratégias mais comuns consistem no simples congelamento de amostras aquosas e posterior análise do sólido resultante.$^{56} \mathrm{Em}$ trabalho proposto por Lee et al..$^{57}$ os autores utilizaram uma bomba peristáltica para produzir um "jato" da amostra, no qual o pulso de laser foi irradiado diretamente. Outras estratégias envolvem a transferência da amostra líquida para substratos não permeáveis como grafite ${ }^{58}$ e placa de metal, ${ }^{59}$ ou para substratos permeáveis como o papel filtro. ${ }^{60}$ Nesses casos, a amostra líquida é depositada nesses substratos e, após secagem do material o substrato é analisado. Dessa forma, os problemas inerentes às análises de líquidos são minimizados, e o processo de análise ocorre de forma análoga às amostras sólidas.

Recentemente Terán et al ${ }^{61}$ propuseram um método de determinação de $\mathrm{Pb}$ em água. Para isso, os autores utilizaram argila funcionalizada para adsorção do $\mathrm{Pb}$. Posteriormente, essa argila foi prensada para obtenção de pastilhas que foram analisadas diretamente pela LIBS. Já Papai et al.$^{62}$ propuseram um método para extração de íons de cobre em solução aquosa em parafina. Para tanto, após a adição de alguns reagentes a $10 \mathrm{~mL}$ de solução aquosa contendo cobre, $700 \mu \mathrm{L}$ de parafina derretida foi adicionada à solução e, após homogeneização em vortex, $600 \mu \mathrm{L}$ dessa parafina foi extraída e posicionada em um suporte de acrílico para secagem e posterior análise direta em LIBS.

Outra estratégia consiste em misturar a amostra líquida com uma solução polimérica de álcool polivinílico (PVA), obtendo-se um filme fino e homogêneo. ${ }^{63}$ Essa estratégia foi aprimorada e utilizada para análise de fertilizantes líquidos ${ }^{64}$ e protetores solares. ${ }^{65} \mathrm{~A}$ estratégia supracitada envolve a mistura da amostra com uma solução de PVA $10 \% \mathrm{~m} \mathrm{v}^{-1}$ e essa mistura é posteriormente submetida a um processo de secagem, sendo obtido filmes poliméricos finos com a amostra encapsulada. Além disso, o processo potencializa a homogeneização das amostras, bem como a avaliação de adição dos elementos $\mathrm{Bi}, \mathrm{Sc}$ e Y como padrões internos líquidos. Nesse caso, os padrões internos foram adicionados juntamente na mistura com a amostra e a solução de PVA, a fim de se obter uma concentração e, consequentemente, um sinal analítico constante após as análises, possibilitando o uso dessas linhas para normalização.

Amostras gasosas também podem ser analisadas por LIBS, todavia, a principal limitação é a configuração instrumental do sistema. Hohreiter e Hahn ${ }^{66}$ analisaram espécies contendo carbono, tais como $\mathrm{CO}, \mathrm{CO}_{2}$ e $\mathrm{CH}_{4}$, em que esses gases eram inseridos em uma câmara e analisados por um sistema LIBS. Sturm \& Noll ${ }^{67}$ obtiveram sinais de emissão de $\mathrm{C}, \mathrm{H}, \mathrm{O}$ e $\mathrm{N}$ em misturas de ar, $\mathrm{CO}_{2}, \mathrm{~N}_{2}$ e $\mathrm{C}_{3} \mathrm{H}_{8}$ em um sistema LIBS equipado com uma câmara de $\mathrm{Al}$ previamente evacuada com auxílio de bomba de vácuo.

Diante do exposto é possível concluir que a etapa de preparo de amostra para análise por LIBS é crítica. Deve-se ter muito cuidado nesse aspecto, pois um preparo inadequado pode refletir diretamente na qualidade dos resultados. Para outras informações e mais detalhes sobre o preparo de amostras por LIBS, sugere-se a leitura do artigo de revisão "Sample treatment and preparation for laser-induced breakdown spectroscopy" 39 e do livro "Métodos de preparo de amostras para análise elementar". ${ }^{40}$

\section{LIBS E QUIMIOMETRIA}

Na química analítica, o termo "quimiometria" foi introduzido por Svante Wold em 1971, para descrever o uso de modelos matemáticos e princípios estatísticos. Atualmente, a quimiometria é definida como uma ciência que emprega uma abordagem multidisciplinar, que inclui também matemática e estatística, e vem se tornando indispensável para pesquisadores modernos de química analítica. ${ }^{68,69}$

O principal objetivo da quimiometria é converter uma grande quantidade de dados em informações significantes e úteis. Inúmeros 
algoritmos computacionais e estatísticos são aplicados para a realização dessa tarefa. A seleção de uma ferramenta quimiométrica dependerá da aplicação analítica desejada. ${ }^{70}$ Em se tratando de análise por LIBS, o uso da quimiometria é praticamente indispensável devido à grande quantidade de dados. A Figura 3 mostra o quanto o uso da LIBS associada a ferramentas quimiométricas vem crescendo ao longo dos anos. De acordo com a base de dados da Web of Science, desde 2001 foram publicados cerca de 375 artigos científicos que utilizaram algum tipo de ferramenta quimiométrica, e desde 2011 esse número vêm crescendo significativamente.

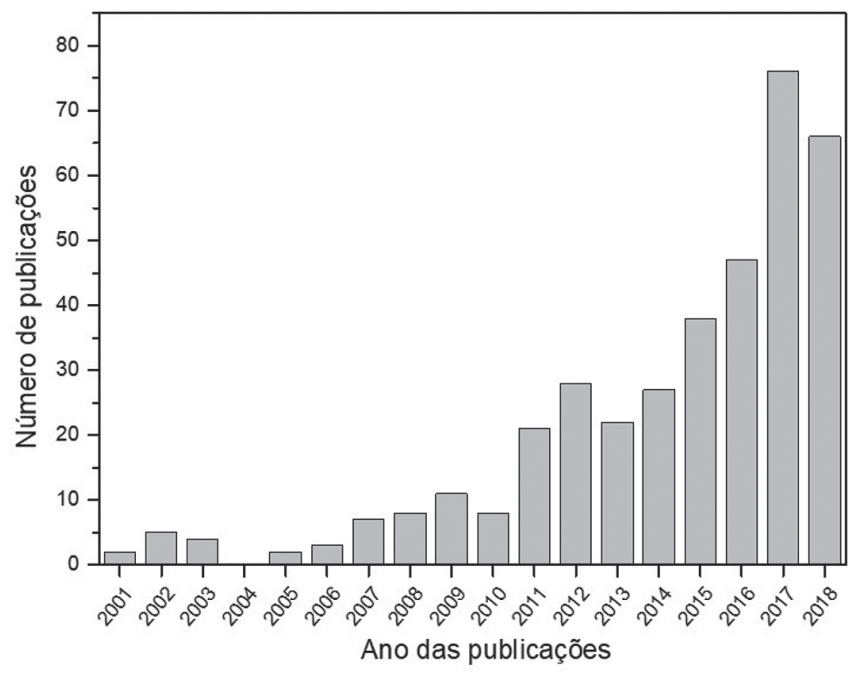

Figura 3. Número de publicações envolvendo LIBS e quimiometria

Os espectros LIBS são muito complexos, devido a alguns fatores relacionados ao ruído do sinal, como: flutuações da energia do laser, taxa de ablação, acoplamento laser-plasma e as características do plasma, sendo caracterizados pelo desvio padrão relacionado ao sinal. Essa complexidade, impossibilita uma aplicação mais ampla da LIBS no campo da química analítica, pois pode afetar as características espectrais (linhas espectrais e emissão contínua). Outro aspecto importante é a homogeneidade ou heterogeneidade do material e a distribuição do analito na matriz da amostra, podendo ser contornado através da área de amostragem. Assim, são necessárias melhorias na precisão das análises qualitativas e quantitativas, reduzindo obstáculos na obtenção de máxima informação útil dos dados. Nessa perspectiva, é notório o sucesso da combinação da LIBS com o uso de ferramentas quimiométricas, as quais auxiliam no melhor entendimento dos dados espectrais. ${ }^{68,71}$

Antes de aplicar alguma ferramenta quimiométrica nos dados LIBS, é recomendado o pré-processamento dos mesmos. Devido à complexidade das interações laser-amostra e laser-plasma e à sensibilidade do plasma frente às características físicas e químicas das amostras, a normalização dos dados é de grande importância, pois minimiza variações indesejadas evitando problemas em análises futuras. Assim, os valores de cada uma das variáveis de uma dada amostra $i$ são divididos por um fator de normalização. ${ }^{71,72}$ Há vários tipos de normalizações que podem ser empregadas para esse propósito, como: normalização pela área total do espectro, pelo sinal que apresenta maior intensidade, pela norma euclidiana do sinal, por padronização interna, entre outras. Além da normalização dos dados, há outros tipos de pré-processamentos empregados nos dados LIBS, a saber: centrar os dados na média para casos em que é utilizado todo o perfil espectral e o autoescalamento para situações em que são empregadas a área ou a altura do sinal (dados discretos). Ambos são muito usados na análise exploratória de dados, proposição de modelos de classificação e de calibração. . $^{73,74}$
A quimiometria pode ser dividida em quatro grandes vertentes: (i) planejamento fatorial e metodologia de superfície de respostas; (ii) análise exploratória de dados químicos; (iii) modelos de classificação; e (iv) calibração multivariada. ${ }^{75-79}$ Todas as vertentes referidas são amplamente empregadas no desenvolvimento de métodos analíticos por LIBS.

Em análises por LIBS, é fundamental otimizar os parâmetros instrumentais, tais como: energia do pulso do laser, tempo de atraso (delay time) e área do pulso (spot size). Esses parâmetros comumente são otimizados através de planejamento experimental a fim de obter uma condição ótima ou de compromisso. ${ }^{80-84}$ Em trabalho proposto por Castro e Pereira-Filho, ${ }^{43}$ a LIBS foi usada para análise direta de ligas metálicas, e as condições instrumentais (energia do pulso do laser, tempo de atraso e área do pulso) foram otimizadas utilizando planejamento do tipo Doehlert. No trabalho proposto por Andrade e Pereira-Filho, ${ }^{85}$ a LIBS foi empregada para análise direta de fertilizantes. As variáveis instrumentais foram avaliadas com o uso de planejamento fatorial fracionário $2^{4-1}$. Nesse caso, não foi possível obter uma condição experimental satisfatória para todos os analitos simultaneamente, assim, uma segunda etapa empregando um planejamento composto central foi usada, a fim de obter uma condição instrumental de compromisso.

Os métodos supervisionados de reconhecimento de padrões, usando as ferramentas quimiométricas SIMCA, partial least squares discriminant analysis (PLS DA), k-nearest neighbor (KNN), e linear discriminant analysis (LDA), são amplamente empregados em LIBS. ${ }^{68} \mathrm{~A}$ utilização dessas ferramentas são indispensáveis quando o objetivo é usar as informações espectrais para proposição de modelos de classificação. As ferramentas referidas foram empregadas com sucesso na proposição de modelos de classificação para amostras de ligas metálicas, ${ }^{43}$ polímeros ${ }^{44} \operatorname{couros},{ }^{86} \cos$ éticos,${ }^{87}$ pinturas pré-histórica, ${ }^{88}$ forense, ${ }^{89}$ rochas vulcânicas ${ }^{90}$ entre outros ${ }^{91-93}$ Os métodos não supervisionados de reconhecimento de padrões, como a principal component analysis (PCA) e hierarchical cluster analysis (HCA) também são empregados. Normalmente, o primeiro passo para interpretação dos dados LIBS para um grande conjunto de amostras é a aplicação da PCA. ${ }^{94-100}$

Outra abordagem quimiométrica muito empregada em análise por LIBS é o uso da calibração multivariada. Dentre as principais ferramentas de calibração multivariada aplicadas estão a partial least squares (PLS), ${ }^{101}$ multiple linear regression (MLR), ${ }^{65}$ artificial neural networks (ANN) $)^{102}$ entre outras. ${ }^{68,103,104}$

Como pode ser observado, é ampla a aplicação da quimiometria nos dados espectrais da técnica LIBS. Apesar de extrair e maximizar informações úteis e melhorar a precisão das análises qualitativas e quantitativas, o universo quimiométrico aplicado a LIBS exige ainda uma maior exploração e pesquisa, visando à melhoria do desempenho da técnica em vários campos de aplicação.

\section{ABORDAGENS PARA ANÁLISE QUALITATIVA E QUANTITATIVA}

A LIBS é uma técnica analítica muito utilizada para análises qualitativas e quantitativas, tendo sido observado um expressivo crescimento nos últimos anos. A Tabela 1 mostra uma variedade de amostras que já foram objeto de estudo por meio da LIBS. Para fins de análise qualitativa, a LIBS é estabelecida e muito utilizada para identificação de elementos químicos. Contudo, para análise quantitativa, requer esforço considerável face às dificuldades para preparação e obtenção de padrões de calibração e a inexistência de materiais de referência com propriedades certificadas para massas de amostra da ordem de $\mu$ g.

Outro fator importante que pode contribuir na qualidade dos resultados quantitativos está no tratamento adequado dos dados obtidos, 
Tabela 1. Abordagens qualitativas e quantitativas em LIBS

\begin{tabular}{|c|c|c|c|c|}
\hline Amostras & Analitos & Tipo de análise & Objetivo & Referências \\
\hline Liga ortopédica & $\mathrm{Ti}$ & Qualitativa & Verificar a presença do Ti em ligas ortopédicas. & [46] \\
\hline Dinitrotolueno (DNT) & $\mathrm{C}, \mathrm{C}_{2}, \mathrm{CN}, \mathrm{H}, \mathrm{N}$ e O & Qualitativa & $\begin{array}{l}\text { Discriminar os três isômeros do DNT }(2,3-, 2,4-\mathrm{e} \\
2,6-) \text {. }\end{array}$ & [105] \\
\hline $\begin{array}{l}\text { Padrões comerciais de } \\
\text { proteína e extrato proteico } \\
\text { de canola }\end{array}$ & $\mathrm{P}$ & Qualitativa & $\begin{array}{l}\text { Identificar proteínas que contenham P em sua com- } \\
\text { posição a partir da análise do gel de eletroforese } \\
\text { (SDS-PAGE)* por LIBS }\end{array}$ & [106] \\
\hline Músculo de suínos & $\mathrm{C}, \mathrm{H}, \mathrm{K}, \mathrm{Mg}$ e $\mathrm{Na}$ & Qualitativa & $\begin{array}{l}\text { Estimar o intervalo post-mortem, que pode ser em- } \\
\text { pregado em abordagens forenses. }\end{array}$ & [107] \\
\hline Pele humana & $\begin{array}{l}\mathrm{Al}, \mathrm{Ca}, \mathrm{Fe}, \mathrm{Mg}, \mathrm{Na}, \mathrm{P} \\
\text { Si e } \mathrm{Zn}\end{array}$ & Qualitativa & $\begin{array}{l}\text { Obtenção de imagens multielementares para biópsia } \\
\text { de amostras de pele humana saudável e com carci- } \\
\text { nomas. }\end{array}$ & [108] \\
\hline Grãos de Café & $\mathrm{C}, \mathrm{C}_{2}, \mathrm{~N}$ e CN & Qualitativa & $\begin{array}{l}\text { Análise qualitativa do café para discriminar os grãos } \\
\text { viáveis daqueles com defeitos (verdes, ardidos ou } \\
\text { pretos). }\end{array}$ & [109] \\
\hline Fertilizantes & $\mathrm{P}$ & Quantitativa & $\begin{array}{l}\text { Avaliar a associação de um sistema de descarga } \\
\text { elétrica ao LIBS, como ferramenta de incremento de } \\
\text { sensibilidade nas determinações de } \mathrm{P} \text { em fertilizantes. }\end{array}$ & [110] \\
\hline Cimentos & $\mathrm{Cl}$ & Quantitativa & $\begin{array}{l}\text { Determinação de } \mathrm{Cl} \text { em cimentos empregando a com- } \\
\text { patibilização de matriz como estratégia de calibração } \\
\text { (padrões preparados com cimento Portland acrescidos } \\
\text { com } \mathrm{NaCl} \text { ). }\end{array}$ & [111] \\
\hline Padrões sintéticos & B & Quantitativa & $\begin{array}{l}\text { Monitorando a emissão molecular para B houve } \\
\text { melhora significativa na exatidão do método, quando } \\
\text { comparado com o monitoramento da linha de emissão } \\
\text { atômica, e utilizando um algoritmo genético e PLS na } \\
\text { proposição dos modelos de regressão. }\end{array}$ & [112] \\
\hline Vegetais & $\mathrm{Cd}$ & Quantitativa & $\begin{array}{l}\text { Determinar Cd em hortaliças empregando PLS como } \\
\text { estratégia de calibração. }\end{array}$ & [113] \\
\hline
\end{tabular}

*SDS-PAGE: sodium dodecyl sulfate polyacrylamide gel electrophoresis

desde a estratégia de correção de linha de base (quando necessária), seleção da linha de emissão do analito, tipo de estratégia de calibração (uni ou multivariada) para o modelo de calibração, entre outros. ${ }^{114}$ Além disso, a LIBS é susceptível a severos efeitos de matriz, o que interfere nos resultados quantitativos. ${ }^{26} \mathrm{~A}$ seguir, apresentaremos as potencialidades da LIBS em análise qualitativa e os avanços em análise quantitativa.

Os espectros LIBS fornecem informações importantes sobre elementos e/ou moléculas, e podem ser utilizados para análise qualitativa a fim de estabelecer impressões digitais (fingerprinting) de uma determinada amostra. Outra possibilidade para fins de análise qualitativa é o uso do mapeamento hiperespectral, que é uma ferramenta que fornece um mapa multielementar da superfície ou do interior de uma determinada amostra. O mapeamento hiperespectral pode ser obtido através dos mapas de escores provenientes de uma PCA,${ }^{53}$ ou mapeando os valores de intensidade de emissão obtidos a partir da ablação de pontos específicos na amostra. ${ }^{115}$

As imagens hiperespectrais podem ser empregadas para avaliar a localização e distribuição espacial de nutrientes em material vegetal, ${ }^{116}$ macronutrientes em alimentos, ${ }^{117}$ elementos perigosos, preciosos e estratégicos em lixo eletrônico, ${ }^{118}$ análises de fósseis e coprólitos, ${ }^{45}$ materiais arqueológicos ${ }^{119}$ e a discriminação entre pele humana saudável e com câncer. ${ }^{108}$

Outra interessante abordagem qualitativa dos espectros LIBS é na identificação e proposição de modelos de classificação, empregando diferentes ferramentas quimiométricas. Senesi et al. ${ }^{120}$ identificaram e classificaram amostras de meteoritos utilizando os espectros obtidos de um equipamento LIBS portátil, usando algoritmo de inferência baseado em lógica fuzzy. Recentemente, Delgado et al. ${ }^{105}$ propuseram um método de discriminação de três isômeros de dinitrotolueno (2,3-, 2,4- e 2,6), empregando a discriminant function analysis (DFA) associada aos espectros LIBS. Inúmeras possibilidades de análise qualitativa são possíveis empregando os espectros multielementares obtidos pela LIBS, de forma rápida (segundos) e fácil, o que a torna uma atraente técnica de caracterização elementar.

$\mathrm{Na}$ análise direta empregando a LIBS, uma porção da amostra é analisada integralmente, assim a matriz da amostra pode influenciar no fenômeno de emissão atômica/iônica/molecular e, consequentemente, no sinal analítico obtido. Desse modo, uma das principais dificuldades relacionadas à determinação quantitativa por LIBS está associada aos efeitos de matriz.

Nesse sentido, diversas estratégias de calibração que visam à análise quantitativa e minimização de efeitos de matriz em LIBS têm sido propostas. Dentre as principais estratégias de calibração estão: (i) compatibilização de matriz; ${ }^{49}$ (ii) adição de padrão; ${ }^{121}$ (iii) padronização interna; ${ }^{122}$ (iv) calibration-free $(\mathrm{CF}) ;{ }^{123}(\mathrm{v})$ one-point calibration (OPC); ${ }^{124}$ (vi) multi-energy calibration (MEC) $;{ }^{47} \mathrm{e}$ (vii) calibração multivariada usando PLS, ${ }^{125}$ MLR, ${ }^{126}$ PCR $^{127}$ e ANN. ${ }^{128}$

Dentre as estratégias de calibração supracitadas, a compatibilização de matriz, provavelmente, é a mais empregada. Para essa estratégia, um conjunto de amostras com concentrações determinadas por uma técnica de referência, ou materiais de referência certificados (MRC) são utilizados como padrões sólidos de calibração. Uma das principais vantagens é que os efeitos de matriz podem ser minimizados quando as propriedades físicas dos padrões de calibração são semelhantes às características das amostras. Apesar de suas vantagens, a obtenção de valores de referência para alguns analitos por outras técnicas pode ser difícil em alguns casos (por exemplo, para amostras 
de difíceis decomposições como o vidro) e quando há um pequeno conjunto de amostras ou MRC. .5,129-132 $^{\text {13 }}$

A calibração por adições de padrão é uma alternativa eficaz para minimizar as principais limitações associadas com LIBS. Nessa estratégia, uma quantidade constante de amostra é adicionada ao branco analítico e em todos os padrões de calibração, garantindo que as amostras e padrões estejam submetidos às mesmas interações físico-químicas com o laser durante a formação do plasma, minimizando assim possíveis efeitos de matriz. As limitações desta abordagem incluem sua incapacidade de corrigir interferências espectrais e a exigência de grandes quantidades de amostra. Além disso, a calibração por adições de padrão pode levar a uma baixa frequência analítica, pois uma curva de calibração com alguns padrões de calibração (geralmente cinco padrões) deve ser preparada para cada amostra individualmente. ${ }^{121,133}$

A padronização interna é uma alternativa de calibração para minimizar as flutuações do sinal analítico, devido às condições instrumentais operacionais, aos erros de amostragem e, em um menor grau, aos efeitos de matriz. ${ }^{134-136}$ Bons resultados têm sido obtidos com esta estratégia de calibração para análise de amostras geológicas e alimentícias complexas. No entanto, a escolha de um elemento como padrão interno apropriado não é tarefa fácil, uma vez que o padrão interno deve sofrer os processos temporais do plasma semelhantes aos dos analitos e possuir propriedades físico-químicas semelhantes, o que geralmente é desafiador em LIBS. ${ }^{137}$ Além disso, a concentração do padrão interno deve estar constante em todas as amostras e padrões analisados, para que a normalização do sinal seja efetiva.

A CF utiliza as intensidades das linhas de emissão e algumas propriedades do plasma, por exemplo, densidade eletrônica do plasma e temperatura, que são calculadas a partir da distribuição de Boltzmann, para determinar a concentração do analito na amostra. Nesse caso, apenas um algoritmo CF é necessário, sem necessidade de uma curva de calibração ou padrões para a compatibilização de matriz. ${ }^{138,139}$ Para que esta estratégia seja empregada é necessário que haja equilíbrio local termodinâmico no plasma gerado na análise das amostras.

A OPC é uma variação do algoritmo $\mathrm{CF}$, que foi proposta para superar a relativa falta de informação sobre alguns parâmetros de transição espectral, bem como compensar parcialmente os efeitos de auto-absorção. ${ }^{124}$ Considerando todos os parâmetros envolvidos na $\mathrm{CF}$ e a complexidade de algumas matrizes, o método é preciso em análises envolvendo amostras fisicamente e quimicamente homogêneas, como ligas metálicas. ${ }^{140,141}$

Recentemente, Babos et al. ${ }^{47}$ empregaram MEC para a determinação de $\mathrm{Ca}, \mathrm{Cu}, \mathrm{Fe}$, Mn e Zn por LIBS, em amostras de suplementos minerais para bovinos. A MEC utiliza apenas dois padrões de calibração, para cada amostra, e vários comprimentos de onda de emissão do analito com diferentes sensibilidades para determinar a sua concentração na amostra. Ambos padrões de calibração são preparados usando a mesma quantidade de amostra, o que contribui para minimizar eficientemente os efeitos de matriz. O padrão 1 é composto por $50 \% \mathrm{~m} \mathrm{~m}^{-1}$ de amostra e $50 \% \mathrm{~m} \mathrm{~m}^{-1}$ de um branco apropriado, enquanto o padrão 2 é composto por $50 \% \mathrm{~m} \mathrm{~m}^{-1}$ de amostra e $50 \% \mathrm{~m}$ $\mathrm{m}^{-1}$ de um padrão de referência contendo os analitos. Para determinar a concentração do analito na amostra é utilizado o coeficiente angular do modelo linear obtido ao preparar um gráfico onde no eixo x estão as intensidades obtidas do padrão 2 (amostra + padrão) e no eixo y, as intensidades obtidas do padrão 1 (amostra + branco), e é considerada a concentração do analito adicionado no padrão 2. Além desse trabalho, essa estratégia foi empregada com sucesso na determinação de $\mathrm{Ca}, \mathrm{K}$ e $\mathrm{Mg}$ em suplementos dietéticos ${ }^{142}$ e na determinação de $\mathrm{Ni}$ e $\mathrm{Cr}$ em minérios níquel-ferrosos. ${ }^{80}$ Algumas limitações desse método estão relacionadas à dificuldade da escolha de um branco apropriado e à homogeneização dos padrões.
As estratégias de calibração multivariadas também proporcionam determinações com satisfatória exatidão e precisão. Algumas limitações intrínsecas de cada método multivariado devem ser conhecidas para que conclusões errôneas não sejam obtidas na calibração do método. A Figura 4 apresenta resumidamente as vantagens e limitações das principais estratégias de calibração (univariada e multivariada) empregadas em LIBS, já mencionadas anteriormente. As possibilidades de calibração para a análise quantitativa por LIBS são diversas, contudo, a melhor calibração será aquela que possibilitar determinações com exatidão e precisão satisfatórias, ou seja, que minimizam os efeitos de matriz na determinação do analito. A escolha da estratégia de calibração empregada no método analítico que será desenvolvido dependerá das propriedades intrínsecas da amostra analisada e do conhecimento das vantagens e limitações inerentes a cada estratégia.

\section{APLICAÇÕES}

A LIBS é uma técnica analítica que vem sendo amplamente empregada para fins qualitativos e quantitativos em uma infinidade de matrizes de interesse nos mais diferentes campos de atuação. Esse crescimento está atrelado às características atraentes da técnica, como a possibilidade de análise direta com mínimo ou nenhum preparo da amostra, a possibilidade de análise in situ, e a sua capacidade multielementar. As aplicações da LIBS podem ser notadas a partir das publicações de artigos de revisão em áreas específicas como: agricultura, ${ }^{143}$ alimentos,,${ }^{144}$ ambiental, ${ }^{145}$ biológicas, ${ }^{146}$ farmacêuticas, ${ }^{147}$ forense, ${ }^{148}$ metalúrgica ${ }^{149}$ e resíduos eletrônicos. ${ }^{5}$ Assim, as áreas de atuação referidas serão abordadas e os mais recentes avanços da LIBS para análise de diversas amostras serão apresentados. Os tópicos a seguir serão organizados a partir das áreas de aplicação com foco em amostras específicas, a saber: agricultura (plantas, fertilizantes e solos), ambiental (água e solos), alimentícia (aspectos nutricionais, segurança alimentar e adulterações), farmacêutica (medicamentos e matéria prima) e biológica (sangue, tecido, cabelo e outros), forense (identificação de resíduos variados e falsificação), resíduo eletrônico (polímeros e printed circuit board (PCB)) e metalurgia (escórias, ligas e aços). A Tabela 2 apresenta um esboço geral acerca das aplicações que serão discutidas nos tópicos subsequentes.

\section{Agricultura}

O interesse da LIBS no amplo campo das ciências agrícolas reside principalmente em sua versatilidade e seu potencial para análises in situ. As aplicações nesse campo de atuação estão entre as mais desafiadoras e concentram-se nas análises de plantas, fertilizantes e solos. ${ }^{88,96}$ Esses desafios se devem basicamente à ampla variedade de amostras e sua complexidade, que refletirá na extensão da interação entre laser-amostra, bem como às condições adversas de trabalho. ${ }^{26,170}$ A seguir, apresentaremos uma revisão sobre os avanços da LIBS para análise de plantas, fertilizantes e solos.

Para fins de análise quantitativa de macro/micronutrientes e contaminantes em plantas, diversos trabalhos já foram publicados, demonstrando as potencialidades da LIBS para esse fim. ${ }^{171-178} \mathrm{O}$ grupo do Prof. Krug do Centro de Energia Nuclear na Agricultura (CENA, Piracicaba - SP) tem se destacado nesse aspecto, e já foram publicadas duas revisões interessantes sobre a aplicação da LIBS para análise de plantas, com enfoque em preparo de amostras e estratégias de calibração. ${ }^{122,179}$

Além da determinação elementar, a LIBS também apresenta grande potencialidade na proposição de modelos de classificação visando à identificação de plantas infectadas. Nessa perspectiva, Pereira et al. ${ }^{180}$ propuseram um método para a classificação de folhas de laranjeira infectadas por citrus greening, baseado nos espectros 


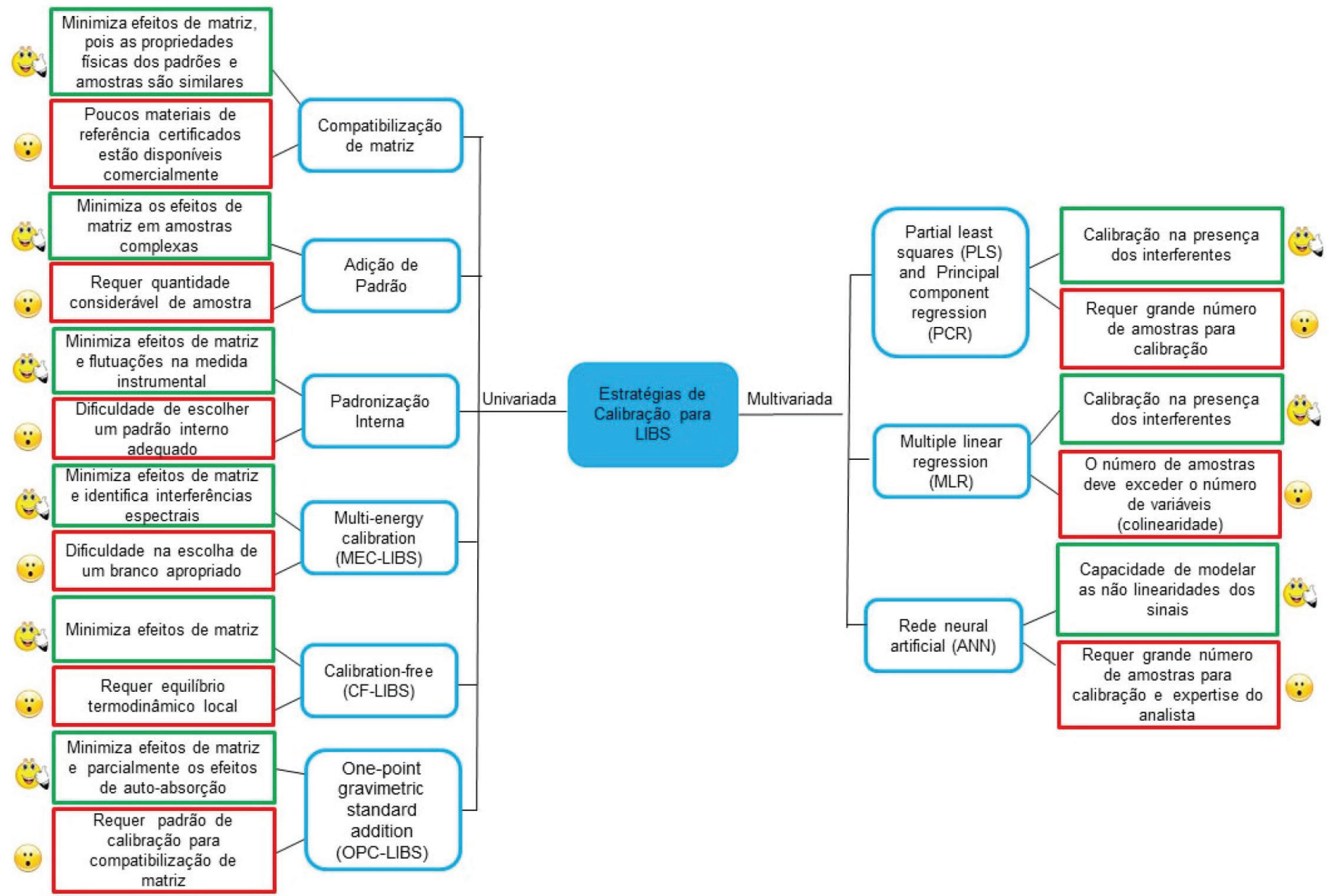

Figura 4. Vantagens e limitações das principais estratégias de calibração univariada e multivariada para análise quantitativa por LIBS

Tabela 2. Campos de atuação e aplicações da LIBS

\begin{tabular}{|c|c|c|c|c|}
\hline Área de aplicação & Objetivo & Amostra & Analitos & Referências \\
\hline \multirow{3}{*}{ Agricultura } & Determinação de nutrientes & Plantas & $\mathrm{K}, \mathrm{Na}$ e $\mathrm{Mn}$ & [41] \\
\hline & Determinação de macro/micronutrientes e contaminantes & Fertilizantes & $\begin{array}{c}\mathrm{Ca}, \mathrm{Cr}, \mathrm{Cu}, \mathrm{Fe}, \mathrm{K}, \mathrm{Mg}, \mathrm{Mn}, \\
\mathrm{Na}, \mathrm{P} \text { e Zn }\end{array}$ & [150] \\
\hline & Determinação do grau de humificação & Solos & Ácido húmico & [151] \\
\hline \multirow{3}{*}{ Alimentos } & Determinação de nutrientes & Chá & $\mathrm{Ca}, \mathrm{Cu}, \mathrm{Fe}$ e $\mathrm{K}$ & {$[152]$} \\
\hline & Determinação de contaminantes & Arroz & $\mathrm{Cd}$ e $\mathrm{Pb}$ & [153] \\
\hline & Adulteração de manteiga com margarina & Manteiga & Margarina & [154] \\
\hline \multirow{2}{*}{ Ambiental } & \multirow{2}{*}{ Determinação de contaminantes } & Água & $\mathrm{Cr}(\mathrm{VI})$ & {$[155]$} \\
\hline & & Solos & $\mathrm{Cr}$ & [156] \\
\hline \multirow{3}{*}{ Biológica } & Determinação de nutrientes e vitaminas & Unhas & $\mathrm{Ca}, \mathrm{K}, \mathrm{Mg}, \mathrm{Na}$ e Vitamina D & {$[157]$} \\
\hline & Discriminação de câncer (linfoma) & Sangue & $\mathrm{Ca}, \mathrm{Fe}, \mathrm{Mg}, \mathrm{K}$ e $\mathrm{Na}$ & [158] \\
\hline & Identificação do intervalo post-morten & Tecido humano & $\mathrm{Mg}, \mathrm{Na}$ and $\mathrm{K}$ & [107] \\
\hline \multirow{3}{*}{ Farmacêutica } & \multirow{3}{*}{ Determinação elementar } & Comprimidos & $\mathrm{Ca}, \mathrm{Cu}, \mathrm{Fe}, \mathrm{Mg}, \mathrm{Mn} \mathrm{P}$ e $\mathrm{Zn}$ & [159] \\
\hline & & Medicamento líquido & $\mathrm{V}$ e Mo & [160] \\
\hline & & Comprimidos & $\mathrm{C}, \mathrm{N}, \mathrm{H}$ e O & [161] \\
\hline \multirow{3}{*}{ Forense } & Resíduos de explosivos em impressões digitais & Impressão digital & MNT, DNT e TNT & [162] \\
\hline & Identificação de documentos & Papel & Documentos governamentais & [58] \\
\hline & Resíduos de explosivos em painel de carros & Painel de veículos & RDX, TNT e composição B & {$[163]$} \\
\hline \multirow{3}{*}{ Metalurgia } & \multirow{3}{*}{ Determinação elementar } & Escórias & $\mathrm{Al}, \mathrm{Ca}, \mathrm{Fe}, \mathrm{Mg}, \mathrm{Mn}, \mathrm{Si}$ e Ti & {$[164]$} \\
\hline & & Ligas & $\mathrm{Al}$ & {$[165]$} \\
\hline & & Aço & $\mathrm{Cr}, \mathrm{Mn}$ e Ni & {$[166]$} \\
\hline \multirow{3}{*}{ Resíduos eletrônicos } & Determinação de contaminantes & Polímeros & $\mathrm{Ba}, \mathrm{Cd}, \mathrm{Cr}$ e $\mathrm{Pb}$ & [167] \\
\hline & Determinação de retardantes de chama em polímeros & Polímeros & $\mathrm{Sb}$ & [168] \\
\hline & Análise de máscaras de solda para PCB & Máscaras de solda & $\mathrm{Ba}$ & [169] \\
\hline
\end{tabular}


de emissão obtidos. O modelo proposto foi promissor para a predição das plantas infectadas. Ainda nessa perspectiva, Ranulfi et al. ${ }^{181}$ empregaram a LIBS na identificação de plantas cítricas, sadias e infectadas com a doença bacteriana huanglongbinh. Os autores observaram que a partir do perfil nutricional é possível propor modelos de classificação para distinguir plantas sadias das doentes. Em outro trabalho, Ranulfi et al. ${ }^{182}$ usaram a LIBS para discriminar plantas de soja sadias e infectadas com a doença conhecida como "haste verde e retenção foliar". A partir da constituição elementar, os autores concluíram que as plantas sadias apresentavam maiores concentrações de $\mathrm{Ca}$ e $\mathrm{Mg}$, já as plantas doentes maiores concentrações de K. Os resultados obtidos demonstram a aplicabilidade da LIBS como uma ferramenta de diagnóstico precoce.

Outra aplicação no campo da análise de plantas por LIBS é o mapeamento químico. O grupo Kaiser's, da República Tcheca, tem se destacado nesse campo de atuação. ${ }^{146,183}$ Nessa perspectiva, Krystofova et al. ${ }^{184}$ realizaram um mapeamento químico, a fim de verificar a distribuição espacial de $\mathrm{Mg}$ e $\mathrm{Pb}$ em folhas de milho, alface e girassol. Nessa mesma abordagem, Guerra et al. ${ }^{185}$ obtiveram mapas químicos de $\mathrm{B}, \mathrm{Ca}, \mathrm{Fe}, \mathrm{Mg}, \mathrm{Mn}, \mathrm{P}$ e Si em fragmentos de folhas secas de cana-de-açúcar por LIBS. O mapeamento químico de plantas pode fornecer informações úteis sobre o diagnóstico nutricional, ou sobre a bioacumulação de possíveis contaminantes em regiões específicas das plantas, como nos frutos e folhas comestíveis. Apesar das potencialidades da LIBS para realização de mapeamento químico, o número de aplicações em plantas ainda é limitado, principalmente pela sensibilidade relativamente baixa da técnica. ${ }^{122}$

A LIBS também tem sido empregada com sucesso para a determinação de nutrientes e contaminantes em fertilizantes. ${ }^{186-188}$ Nessa abordagem, Morais et al. ${ }^{138}$ determinaram Ca em fertilizantes, e avaliaram o uso do Na como padrão interno. Em outro trabalho, Morais et al. ${ }^{189}$ determinaram $\mathrm{K}$ em fertilizantes e avaliaram o uso da adição sais de elementos facilmente ionizáveis, afim de melhorar a sensibilidade da LIBS, e os resultados foram muito promissores. Já Vieira et al. ${ }^{110}$ desenvolveram um método para determinação de P em fertilizantes. Os autores utilizaram um sistema de descarga elétrica acoplada a um LIBS de baixa energia do pulso $(50 \mathrm{~mJ})$, a fim de melhorar a sensibilidade. Os resultados apresentados pelos autores mostraram que essa abordagem é muito consistente e promissora. Andrade e Pereira-Filho ${ }^{85}$ determinaram nutrientes (B, $\mathrm{Cu}, \mathrm{Ca}, \mathrm{Mg}$, $\mathrm{Mn}, \mathrm{Na}$ e $\mathrm{Zn}$ ) e contaminantes ( $\mathrm{Cd}, \mathrm{Cr}$ e $\mathrm{Pb})$ em fertilizantes sólidos. Nesse trabalho, as concentrações de $\mathrm{Pb}$ encontradas foram alarmantes, variando de 0,1 a $1(\% \mathrm{~m} / \mathrm{m})$. Os resultados apresentados indicam que a LIBS é uma ferramenta viável para determinar nutrientes e contaminantes em fertilizantes, e pode ser empregada na análise de rotina.

A aplicação da LIBS para análise de fertilizantes está restrita aos fertilizantes sólidos, que são os mais empregados na agricultura. Contudo, o uso dos fertilizantes líquidos tem ganhado destaque nos últimos anos, uma vez que os mesmos podem ser aplicados diretamente nas folhas das plantas e proporcionam maior disponibilidade de nutrientes e eficiência de fertilização em curto prazo. No entanto, como já discutido na seção sobre preparo de amostras, a análise de líquidos por LIBS ainda é um desafio a ser superado. Nesse sentindo, Andrade et al. ${ }^{64}$ propuseram um novo método de preparo de amostras para análise de fertilizantes líquidos (suspensão) em LIBS. As amostras de suspensão de fertilizantes foram misturadas com PVA $10 \% \mathrm{~m} / \mathrm{v}$ e mantidas por aproximadamente $2 \mathrm{~h}$ a $50^{\circ} \mathrm{C}$, resultando em um fino filme polímerico com a suspensão líquida imobilizada. Posteriormente, esse filme polimérico foi introduzido na câmara de ablação da LIBS e analisado. Os resultados apresentados pelos autores demonstraram que o procedimento proposto de preparo de amostras líquidas possui um alto potencial para o desenvolvimento e implementação de métodos para determinação de $\mathrm{Cu}, \mathrm{K}, \mathrm{Mg}, \mathrm{Mn}$ e Zn em suspensões de fertilizante e em outras amostras de difícil mineralização.

Outra aplicação da LIBS contempla a análise de solos e algumas revisões sobre esse tema demonstram a potencialidade da técnica nesse campo. ${ }^{120,190,191} \mathrm{~A}$ seguir, apresentaremos as principais demandas das ciências agrícolas para análise de solos usando LIBS. Nessa perspectiva, a LIBS vem sendo amplamente empregada para a determinação quantitativa de macro e micronutrientes. ${ }^{192-197}$ Além da determinação de macro e micronutrientes, a LIBS tem sido utilizada para outros fins em análise de solos. Nesse sentido, Pontes et al. ${ }^{198}$ usaram a LIBS, associada a ferramentas quimiométricas (modelos de classificação), para classificar diferentes tipos de solos (argissolo, latossolo e nitossolo) brasileiros. O método proposto foi aplicado com sucesso e a taxa de acerto para os modelos foi de $90 \%$. Já Nicolodelli et al. ${ }^{199}$ determinaram o teor de carbono em amostras de solos da região amazônica e de mata atlântica. Ainda nessa perspectiva, Ferreira et al..$^{200}$ usaram a LIBS para avaliar o grau de humificação de matéria orgânica no solo. Em outro trabalho, Ferreira et al. ${ }^{201}$ propuseram um método para determinar o $\mathrm{pH}$ de solos. Os resultados alcançados foram promissores e estavam em concordância com aqueles obtidos pelo método de referência usando potenciometria.

Por outro lado, Villas-Boas et al. ${ }^{202}$ expandiram a aplicação da LIBS para análise da textura de solo. Modelos de calibração foram propostos para estimar a proporção de areia, silte e argila em amostras de solo de composição variada. Os resultados foram promissores e a incerteza apresentada pelo método proposto foi semelhante à incerteza do método de referência. Em trabalho proposto por Tadini et al. ${ }^{203} \mathrm{a}$ LIBS foi empregada para avaliação das frações de ácido húmico e ácido fúlvico em solos da Amazônia. Os resultados mostraram que a fração de ácido fúlvico foi associada com altas quantidades de Al nos solos, enquanto a fração de ácido húmico foi mais seletiva em relação ao Fe.

\section{Alimentos}

Nós últimos anos, a LIBS tem se consolidado como uma ferramenta valiosa para análise de amostras alimentícias. ${ }^{204}$ De acordo Sezer et al. ${ }^{144}$ as aplicações da LIBS em ciências de alimentos estão centradas principalmente na avaliação dos aspectos nutricionais (macro e microelementos), toxicológicos (contaminantes) e de adulteração. Ainda segundo Sezer et al. ${ }^{144}$ do total das publicações envolvendo LIBS e alimentos, os aspectos nutricionais, toxicológicos e de adulteração respondem por cerca de $62 \%, 31 \%$ e $8 \%$ respectivamente. Nesse sentido, apresentaremos algumas das mais recentes contribuições da LIBS em ciência de alimentos, com ênfase nos aspectos anteriormente mencionados. A LIBS tem se revelado como uma técnica versátil para análise elementar de diferentes tipos de amostras alimentícias, tais como chá, ${ }^{81}$ carne, ${ }^{132}$ arroz, ${ }^{205}$ café, ${ }^{206}$ grão de bico, ${ }^{207}$ farinhas sem glúten ${ }^{208}$ e farinha de mandioca. ${ }^{209}$

Diversos trabalhos usaram a LIBS para a avaliação dos aspectos nutricionais, a partir da determinação de macro e microelementos essenciais. ${ }^{81,132,205,208-210}$ Nesse sentido, Ferreira et al. ${ }^{211}$ determinaram Ca em amostras de cereais matinais. Peruchi et al..$^{52}$ analisaram amostras de farinhas de trigo pastilhadas para a determinação de $\mathrm{Ca}, \mathrm{Cu}, \mathrm{Fe}$, $\mathrm{K}, \mathrm{Mg}, \mathrm{Mn}, \mathrm{P}, \mathrm{S}$ e $\mathrm{Zn}$ utilizando LIBS e espectrometria de fluorescência de raios $\mathrm{X}$ por energia dispersiva. Em outro estudo, Bilge et $a l .{ }^{212}$ determinaram $\mathrm{Na}$ em biscoitos e diferentes tipos de pães. Já Singh et al. ${ }^{213}$ determinaram $\mathrm{Ca}, \mathrm{K}, \mathrm{Mg}$ e Na presentes nos grãos de sementes de abóbora, melancia e melão. Recentemente, Zivkovic et $a l .{ }^{214}$ determinaram Ba e Mn em amostra de chá de hortelã. Como estratégia de calibração, os autores usaram o método de adição de padrão e os resultados estavam em concordância com o método de referência por ICP OES. 
Além da determinação elementar, a LIBS também é uma poderosa ferramenta para avaliar outros componentes nutricionais como, proteínas, gorduras saturadas, carboidratos e teor de cinzas. ${ }^{144,204}$ Kongbanga et al. ${ }^{215}$ monitoraram o sinal de emissão da banda de $\mathrm{C}_{2}$, emitida por diferentes óleos vegetais e propuseram um método para determinação quantitativa de ácidos graxos saturados. Sezer et al. ${ }^{216}$ desenvolveram um método para análise de proteínas nitrogenadas em amostras de farinhas de trigo. O teor de nitrogênio foi correlacionado com o teor de proteína na farinha de trigo, e a análise elementar foi usada para determinar seus compostos orgânicos. Em outro estudo, Bilge et al. ${ }^{217}$ focaram na análise de cinzas em farinha de trigo. $\mathrm{O}$ teor de cinza é um parâmetro de qualidade importante em termos de rotulagem nutricional, bem como nas propriedades de processamento de vários produtos de cereais.

Além da composição nutricional, a detecção de contaminantes (elementos tóxicos e agentes biológicos) é uma questão importante na indústria de alimentos. ${ }^{144,204}$ Apesar dos vários atrativos da LIBS, os altos LOD podem limitar sua aplicação nesse campo. Alguns trabalhos têm usado a LIBS para detecção de metais tóxicos em alimentos, mas geralmente as concentrações estão no nível de $\mathrm{mg} \mathrm{kg}^{-1}$. Nesse sentido, Lin et al..$^{218}$ avaliaram a concentração de $\mathrm{Pb}\left(\mathrm{mg} \mathrm{kg}^{-1}\right)$ em amostras de laranja empregando LIBS e calibração multivariada. Já Ponce et al. ${ }^{219}$ determinaram $\mathrm{Pb}\left(\mathrm{mg} \mathrm{kg}^{-1}\right)$ em amostras de peixes, particularmente na tilápia do Nilo (Oreochromis niloticus), e Yao et al. ${ }^{220}$ determinaram $\mathrm{Cd}\left(\mathrm{mg} \mathrm{kg}^{-1}\right)$ em amostra de vegetais.

Contudo, as aplicações da LIBS não estão restritas apenas a sua capacidade de determinação elementar, e vários autores têm explorado as demais potencialidades da técnica para monitorar outros contaminantes em amostras alimentícias. Nesse sentido, Multari et al. ${ }^{221}$ detectaram contaminantes biológicos (Escherichia coli e Salmonella entérica) em vários produtos como casca de ovo, leite, carne e alface. Em outro trabalho, os autores caracterizaram o leite proveniente de vacas infectadas com mastite, avaliando apenas as bandas de emissão de $\mathrm{CN}$ e $\mathrm{C}_{2}$ do espectro LIBS. Além de elementos tóxicos e agentes biológicos, outro contaminante comum em amostras alimentícias é o resíduo de agrotóxicos. Nesse contexto, Kim et al. ${ }^{222}$ discriminaram amostras de arroz e espinafre contaminadas com pesticidas, enquanto Ma e Dong ${ }^{223}$ investigaram a potencial aplicação da LIBS para a detecção de resíduos do inseticida clorpirifós em cascas de maçã. Huiqin et al..$^{224}$ desenvolveram um modelo de calibração para detecção de resíduos de fungicidas cúpricos em casca de laranja.

As aplicações da LIBS em análise de alimentos são amplas e a versatilidade da técnica permite sua aplicação no campo das adulterações. A avaliação de adulterantes em amostras alimentícias é uma grande preocupação para agências reguladoras, órgãos governamentais, consumidores e fabricantes. ${ }^{144,204}$ Nesse cenário, a LIBS se encaixa satisfatoriamente devido a sua alta frequência analítica e possibilidade de análise direta. Uns dos principais alimentos alvos de adulteração são os produtos cárneos. Para esse fim, Bilge et al..$^{225}$ determinaram a taxa de adulteração nas misturas de carne de porco, de frango e de vaca. Para determinar a adulteração de miudezas em carne bovina, Casado-Gavalda et al. ${ }^{226}$ usaram a LIBS para análise quantitativa do teor de $\mathrm{Cu}$ em amostras de carne processada, enriquecida com fígado bovino. Dixit et al..$^{227}$ detectaram adulteração de carne bovina com rim de boi. Os produtos derivados do leite também são alvos de adulterações, principalmente pela sua importância econômica. Bilge $e t a l .^{212}$ avaliaram quantitativamente a adulteração de soro em pó em leite em pó, usando LIBS associada a ferramentas quimiométricas. Moncayo et al. ${ }^{128}$ detectaram a presença de melamina no leite. A adulteração também é um problema que acomete a indústria de óleos vegetais. Para este fim, Caceres et al..$^{228}$ usando LIBS combinada com ANN, propuseram um método para identificação, controle de qualidade, rastreabilidade e detecção de adulteração em azeites extra virgem.
A LIBS também foi empregada para avaliar a adulteração de açafrão com alguns adulterantes como cártamo, cravo-de-defunto e cúrcuma.

As aplicações da LIBS na análise de alimentos extrapolaram suas aplicações para além das características acima mencionadas, e vêm sendo utilizadas para avaliação da origem geográfica de produtos alimentícios. Nesse seguimento, Moncayo et al. ${ }^{229}$ usaram a LIBS em combinação com a quimiometria para classificar amostras de vinhos tintos com base em sua origem geográfica.

\section{Ambiental}

Nos últimos anos, aproximadamente $15 \%$ das publicações com LIBS foram destinadas à análise de amostras ambientais. Grande parte dessas publicações estão voltadas para a determinação de contaminantes em água e solos. ${ }^{148,230}$ No que se refere à análise de água (amostras líquidas) por LIBS, as dificuldades são potencializadas, como já discutido na seção "preparo de amostras". No trabalho proposto por Sobral et $a l .{ }^{56}$ um método para determinação de $\mathrm{Hg}$, $\mathrm{Cd}$ e $\mathrm{Pb}$ em águas contaminadas foi proposto com sucesso. Os LOD obtidos para as amostras analisadas na forma líquida foram de 21, 7, e $12 \mathrm{mg} \mathrm{L}^{-1}$; em comparação aos LOD para amostras analisadas na forma sólida (os autores converteram a amostra líquida para sólida), estes foram de 4, 2 e $1 \mathrm{mg} \mathrm{L}^{-1}$, respectivamente. Os altos valores de LOD apresentados pela LIBS limitam a sua aplicação na determinação de contaminantes em amostras de água, impossibilitando o desenvolvimento de métodos sensíveis que atendam às exigências dos órgãos reguladores. A fim de contornar essa limitação, alguns trabalhos têm utilizado com sucesso métodos de pré-concentração. Em um trabalho recente, proposto por Carvalho et al. ${ }^{231}$ a pré-concentração foi usada para separar espécies de Cr (III) e Cr (VI). A estratégia foi aplicada em amostras de água de abastecimento público e os LOD obtidos estavam abaixo do estabelecido pelo Conselho Nacional do Meio Ambiente (CONAMA), que são de $1 \mathrm{mg} \mathrm{L}^{-1}$ para Cr (III) e $0,1 \mathrm{mg}$ $\mathrm{L}^{-1}$ para Cr (VI). Nessa mesma abordagem, Ruiz et al..$^{232}$ usaram a extração em fase sólida para a pré-concentração simultânea de $\mathrm{Cd}, \mathrm{Cr}$, $\mathrm{Mn}, \mathrm{Ni}, \mathrm{Pb}$ e $\mathrm{Zn}$ em amostras de água. Os autores usaram o grafeno como material adsorvente e o método proposto foi aplicado com sucesso. Além disso, os valores de LOD mostraram-se adequados atendendo às exigências dos órgãos reguladores. Diante do exposto, é possível observar que as estratégias de pré-concentração podem ser uma alternativa viável para a análise de amostras ambientais por LIBS. Além disso, essa estratégia elimina possíveis efeitos de matriz, o que é muito atraente em determinações por LIBS.

Para determinação de contaminantes em solos, a LIBS vem sendo utilizada com bastante êxito, contudo, as concentrações normalmente estão na faixa de $\mathrm{mg} \mathrm{kg}^{-1}$. Nesse sentido, Sirven et al. ${ }^{233}$ determinaram $\mathrm{Cr}$ em solos contaminados e as concentrações encontradas estavam entre 62 e $560 \mathrm{mg} \mathrm{kg}^{-1}$. Santos et al..$^{50}$ desenvolveram um método para determinação de $\mathrm{Cd}$ na faixa de $\mathrm{mg} \mathrm{kg}^{-1} \mathrm{em}$ amostras de solos. Em trabalho proposto por Pandhija et al ${ }^{234}$ a CF-LIBS foi utilizada como estratégia de calibração para determinação de $\mathrm{Cd}, \mathrm{Co}, \mathrm{Pb}, \mathrm{Zn}$ e Cr em amostras de solos da Índia. Mukhono et al. ${ }^{235}$ exploraram as ferramentas quimiométricas para reduzir complexidade dos espectros LIBS, visando à determinação $\mathrm{Cr}$ e $\mathrm{Pb}$ em amostras de solos. Como estratégia de calibração, as ANN e PLS foram empregadas com sucesso.

Recentemente, Zaytsev et al. ${ }^{236}$ avaliaram diferentes estratégias de calibração (univariada e multivariada) para posterior determinação de $\mathrm{Pb}$. Segundo os autores, houve uma boa concordância entre os valores de concentração previstos pela LIBS e pela técnica de referência ICP OES. Além disso, o método proposto apresentou LOD da ordem de $13 \mathrm{mg} \mathrm{kg}^{1}$ e mostrou-se adequado para determinação de $\mathrm{Pb}$ em solos. Em trabalho proposto por Yi et al..$^{237}$ foi realizada a determinação de 
$\mathrm{Cd}$ e $\mathrm{Pb}$ em solos. Nesse trabalho, foi proposto um método simples de pré-tratamento de amostras denominado transformação sólido-líquido-sólido. Por este método, metais potencialmente tóxicos disponíveis foram extraídos do solo através de extração ultrassônica e, em seguida, depositados em uma lâmina de vidro. Utilizando este método de transformação sólido-líquido-sólido, os elementos de $\mathrm{Cd}$ e $\mathrm{Pb}$ disponíveis no solo foram detectados com sucesso.

\section{Biológicas e farmacêuticas}

A versatilidade da LIBS amplia sua aplicação no campo das ciências biológicas e farmacêuticas. A combinação entre LIBS e ciências biológicas tem sido comumente chamada pela comunidade científica de bio-LIBS. ${ }^{148}$ As aplicações biológicas em LIBS são principalmente de natureza qualitativa, mas também ocorrem análises quantitativas. A aplicação da bio-LIBS estende-se a uma ampla variedade de amostras como, sangue, ${ }^{158}$ cabelo, ${ }^{238}$ unhas, ${ }^{239}$ fígado de pacientes com mal de Wilson, ${ }^{240}$ urina, ${ }^{241}$ e dentes. ${ }^{242}$

O grande potencial da LIBS nesse campo é que não é necessário nenhum conhecimento prévio sobre as sequências de ácido nucléico ou anticorpos contra antígenos bacterianos conhecidos, em contraste com as técnicas de diagnóstico clínico estabelecidas. Além disso, pouca ou nenhuma preparação de amostra é necessária. ${ }^{148}$ Nesse sentido, Gaudiuso et al. ${ }^{243}$ usaram a bio-LIBS para identificação de câncer de pele (melanoma) utilizando amostras de sangue provenientes de camundongos saudáveis e doentes. Os autores adquiriram os espectros usando um instrumento LIBS com laser de femto segundos. As intensidades de emissão obtidas para ambas as amostras de sangue foram submetidas a diferentes substratos e testadas com métodos de classificação. A combinação entre o substrato e o modelo de classificação mais adequado permitiu aos autores discriminar, com até 96 $\%$ de exatidão, as amostras de sangue dos camundongos saudáveis e doentes.

O campo de atuação da bio-LIBS ampliou-se para a identificação de patógenos, como bactérias e vírus. Uma das principais vantagens no uso da bio-LIBS para identificação de patógenos é que os espectros de emissão obtidos não sofrem alterações com o passar do tempo, diferentemente das culturas bacterianas e virais. ${ }^{148}$ Nos trabalhos de Putnam et al..$^{244}$ e Manzoor et al..$^{245}$ a bio-LIBS foi usada com sucesso para identificar bactérias patógenas e não patógenas, além de cepas resistentes à drogas, como a Staphylococcus aureus e outras cepas que causam infecções hospitalares. Entretanto, os autores não dão detalhes sobre a especificidade dos métodos propostos, pois a mesma linha de emissão pode ser associada ao patógeno e também aos constituintes da amostra. A bio-LIBS também vem sendo usada para identificação de infecções provenientes de fungos, como a Candidíase. Nesse sentido, Manzoor et al. ${ }^{246}$ propuseram um método para discriminar diferentes espécies de Candida a partir de uma variedade de cepas utilizando LIBS em combinação com ANN. Dessa forma, foi possível identificar e discriminar com sucesso 21 variedades de cepas, sem falsos positivos ou falsos negativos.

Em trabalho proposto por Almessiere et al. ${ }^{157}$ um novo método para a identificação de pessoas com deficiência de vitamina $D$ foi desenvolvido e apresentou boa exatidão. Unhas de pacientes previamente identificados com a deficiência foram analisadas por LIBS. A partir das linhas de emissão, foi possível obter uma correlação entre a deficiência de vitamina $\mathrm{D}$ e a intensidade de alguns elementos. As linhas de K apresentaram alta correlação com a deficiência de vitamina D. Já o Ca e Mg mostraram baixa correlação com a deficiência de vitamina D. Uma outra aplicação biológica da LIBS muito relevante foi reportada por Davari et al. ${ }^{247}$ na qual os autores desenvolveram um método analítico para a análise in vitro de células intersticiais valvares (VICs), visando à determinação de Ca nos diferentes estágios de sua deposição na artéria aorta (doença conhecida como calcificação da aorta). Os autores observaram uma excelente correlação entre os resultados obtidos a partir de um ensaio bioquímico e aqueles do método proposto.

A LIBS também é aplicada para a análise de fármacos, bem como de sua matéria-prima. Nesse sentido, Anzano et al. ${ }^{248}$ desenvolveram dois métodos rápidos para identificação e caracterização de diferentes analgésicos em comprimidos, com excelente correlação entre os espectros obtidos para os comprimidos e os espectros de referência provenientes de uma biblioteca de espectros, e também a partir da calibração realizada por meio das razões $\mathrm{C}: \mathrm{C}_{2}: \mathrm{H}: \mathrm{N}: \mathrm{O}$, cujos sinais foram obtidos pela ablação de uma variedade de comprimidos. Já Myakalwar et al. ${ }^{161}$ e Tiwari et al. ${ }^{249}$ utilizaram a LIBS em combinação com ferramentas quimiométricas para a identificação e classificação de comprimidos, visando ao aumento da velocidade no processo de controle de qualidade das indústrias farmacêuticas. Em trabalho proposto por Carvalho et al..$^{159}$ as concentrações de macro $(\mathrm{Ca}, \mathrm{Mg}$ e P) e microelementos ( $\mathrm{Cu}, \mathrm{Fe}, \mathrm{Mn}$ e $\mathrm{Zn}$ ) foram determinadas em comprimidos farmacêuticos. Os valores previstos pela LIBS estavam em concordância com aqueles obtidos pela técnica de referência usando ICP OES. Dubey et al. ${ }^{250}$ utilizaram a LIBS na proposição de um método para análise de diferentes revestimentos de comprimidos. A LIBS também foi explorada com sucesso para análise de amostras líquidas farmacêuticas, no qual os autores associaram a microextração líquido-líquido dispersiva (DLLME) para a determinação de V e Mo com a obtenção de sinais pela LIBS. Os autores reportaram uma melhora significativa da sensibilidade e diminuição dos efeitos de matriz. ${ }^{160}$

\section{Forense}

A rapidez da análise, manutenção da integridade da amostra e a capacidade de fornecimento de informações espectrais com a finalidade de classificação e/ou identificação são características atraentes da LIBS. Assim, a ampliação das suas aplicações para análise de amostras forense é uma questão natural. Amostras de caráter forense são comumente oriundas de investigações de fraudes, de esforços antiterrorismo ou de atividades após grandes desastres. ${ }^{148}$

Utilizando todas as vantagens proporcionadas pela LIBS, Cahoon et $a l^{251}$ realizaram a caracterização de fragmentos de vidros provenientes de cenas de crime, de modo que, nesse caso, os autores comprovaram que a irradiância do laser de $266 \mathrm{~nm}$ é a mais adequada para promover o acoplamento laser-amostra. Nos trabalhos propostos por Lucia e Gottfried ${ }^{163}$ e Gottfried, ${ }^{252}$ foram desenvolvidos métodos para a detecção e classificação de explosivos. A LIBS também foi empregada com sucesso durante investigações forenses para a discriminação de diferentes tipos de papel e tinta usados em impressões digitais, ${ }^{253}$ de tintas usadas para escrita. ${ }^{254}$ Além disso, também foi usada para diferenciar papéis e tintas de canetas de acordo com sua composição química ${ }^{255}$ e para identificação da origem de charutos artesanais. ${ }^{256}$ A LIBS também foi aplicada para avaliar a veracidade de documentos de identificação, como passaportes e identidades. ${ }^{257}$ Recentemente, Yang e Yoh ${ }^{258}$ usaram a LIBS para análise de impressões digitais sobrepostas, visando à sua separação e classificação utilizando ferramentas quimiométricas. Nesse estudo, os autores obtiveram os espectros referentes à composição química das impressões digitais de indivíduos em cenas de crime e, após classificação, conseguiram reconstruir essas impressões digitais utilizando análise estatística multivariada para estimar a sequência de tempo na qual uma impressão digital foi marcada. Em outro trabalho, Yang e Yoh ${ }^{90}$ também reconstruíram impressões digitais de indivíduos em cenas de crime a partir de impressões digitais sobrepostas, empregando os espectros obtidos por LIBS e ferramentas quimométricas. 
Marín-Roldan et al. ${ }^{107}$ analisaram tecidos e músculos humanos para discriminar indivíduos post-mortem, bem como o intervalo post-mortem dos mesmos em cenas de crimes e desastres naturais. E em outra abordagem, a partir de fragmentos de dentes e ossos humanos, Moncayo et al. ${ }^{259}$ desenvolveram um método analítico simples, rápido e não destrutivo, combinando LIBS e quimiometria para discriminar e classificar restos cadavéricos de vítimas de desastres.

A possibilidade de análise in situ e a obtenção do perfil de profundidade de uma amostra foram características importantes no desenvolvimento de um método descrito por Choi e Yoh $^{260}$ para a obtenção de informações químicas em resíduos de combustão por LIBS, após um incêndio premeditado. Os autores concluíram que os espectros obtidos a partir dos resíduos do incêndio e a espessura da camada de carbono das amostras queimadas trazem informações químicas que podem auxiliar investigações relacionadas a incêndios criminosos. Em outra abordagem, Bhatt et al. ${ }^{261}$ analisaram material nuclear e radiológico, visando a contribuir com o monitoramento e a segurança destes. Os autores conseguiram determinar a concentração de urânio em minérios e o uso da PCA possibilitou a classificação das amostras quanto a sua origem mineralógica. Uma outra aplicação relevante da LIBS na área forense foi chamada de iForenLIBS, tecnologia desenvolvida por Doña-Fernández et al. ${ }^{262}$ para analisar in situ partículas de resíduos de disparos que são projetadas aleatoriamente na cena do crime, a partir da determinação simultânea de $\mathrm{Pb}, \mathrm{Ba}$ e $\mathrm{Sb}$, com aquisição dos resultados em tempo real.

\section{Metalurgia}

A LIBS é uma ferramenta atrativa para a análise de produtos advindos da indústria metalúrgica, e vem se tornando uma técnica promissora devido as suas características peculiares. ${ }^{43,149}$ Nesse contexto, as ferramentas quimiométricas têm ganhado destaque junto aos métodos analíticos desenvolvidos para análise de ligas metálicas e demais amostras relacionadas ao setor metalúrgico por LIBS. Dentre as principais amostras analisadas por LIBS estão as escórias, ligas e aços. Nesse sentido, Zhang et al. ${ }^{263}$ determinaram $\mathrm{Al}, \mathrm{Ca}, \mathrm{Mg}, \mathrm{Si}$ e Ti em amostras de escória de minério usando LIBS e calibração multivariada. Na mesma perspectiva, Ahamer et al. ${ }^{264}$ determinaram diferentes óxidos em amostras de escória obtidas a partir da indústria de aço utilizando modelos de calibração multivariada e CF-LIBS. Kolmhofer et al. ${ }^{164}$ também analisaram escórias provenientes da produção de aço empregando CF-LIBS e reportaram que a combinação entre a LIBS e essa estratégia de calibração é promissora, ressaltando a adequabilidade desse método para análise de amostras complexas.

Nas indústrias de ferro e aço, o monitoramento da composição elementar em amostras de aço é importante para assegurar a qualidade na produção, por isso o uso da LIBS foi uma alternativa adequada no desenvolvimento de um método analítico para análise in situ de amostras de aço fundido para determinação de Cr, Mn, Ni, Si e V usando modelos PLS. ${ }^{265}$ Além dos constituintes inorgânicos comumente determinados em aço, a LIBS também apresenta potencial para a determinação de elementos não metálicos, como o S e P. ${ }^{266}$ Lin et $a l .{ }^{267}$ propuseram dois métodos para classificação de aço usando LIBS e ferramentas quimiométricas: no primeiro, os autores empregaram PLS e, no segundo, support vector machine (SVM). Além disso, os autores utilizaram o algoritmo SVM de least squares (LSSVM) para melhorar a identificação das classes de aço, conferindo posteriormente identificação com $100 \%$ de acerto quando a combinação LIBS e LSSVM foi empregada para identificação de amostras de aço de composição similar.

Castro e Pereira-Filho ${ }^{43}$ propuseram a análise direta de ligas metálicas e aço empregando modelos de regressão univariada e multivariada para a determinação de $\mathrm{Al}, \mathrm{Cr}, \mathrm{Cu}, \mathrm{Fe}, \mathrm{Mn}, \mathrm{Mo}, \mathrm{Ni}, \mathrm{Ti}, \mathrm{V}$ e
Zn, e a proposição de modelos de classificação para a discriminação das amostras. Ligas de alumínio, ${ }^{165}$ aço, ${ }^{266}$ aço de liga leve, ${ }^{268}$ ligas de $\mathrm{Ge} / \mathrm{Si}^{269}$ também foram analisadas diretamente por LIBS para a quantificação de constituintes inorgânicos. He et al. ${ }^{270}$ empregaram a LIBS e um laser-ablation spark-induced breakdown spectroscopy (LA-SIBS), ambos com laser de femto segundos, para determinação de $\mathrm{Cr}, \mathrm{Mn}, \mathrm{Mg}$ e $\mathrm{Cu}$ em ligas de alumínio. Nesse método, os autores conseguiram melhorar significativamente a precisão dos resultados e a alta frequência de amostragem. Em todos esses trabalhos reportados, a LIBS foi efetiva para a quantificação dos analitos, de forma direta, rápida e sem interferências (espectrais ou de matriz), o que são aspectos importantes a serem considerados pelo setor metalúrgico, visando a um controle de qualidade eficiente e rápido (em tempo real) dos seus produtos.

\section{Resíduos eletrônicos}

Os resíduos de equipamentos elétrico e eletrônico (REEE) são compostos basicamente por ferro/aço, polímeros, retardantes de chama (FR), metais não ferrosos, vidro e PCB. ${ }^{271-273}$ Dentre os componentes do REEE mencionados, os polímeros e as $\mathrm{PCB}$ respondem por cerca de 21 e $4 \%$ da fração total, respectivamente. ${ }^{274-276}$ Esses materiais são reaproveitáveis, e nesse sentido, existem vários trabalhos na literatura que usam a LIBS como ferramenta para análise preliminar de REEE, visando à destinação adequada desses materiais. Contudo, essas análises estão restritas majoritariamente aos polímeros e em alguns casos têm sido aplicadas às PCB. Essa discrepância, pode ser observada em termos de números de trabalhos publicados com o tema. De acordo com a base de dados da Web of Science, desde 1998, quando se deram as primeiras publicações com o tema, cerca de 75 trabalhos já foram publicados. Deste montante, os polímeros respondem por $90 \%$ das publicações e as PCB por $10 \%$. Essa temática tem despertado o interesse de grupos de pesquisa e recentemente foi publicada a primeira revisão com tema. ${ }^{5}$

Neste tópico nós apresentaremos as principais contribuições e os mais recentes avanços da LIBS na análise direta de REEE, visando ao desenvolvimento de métodos analíticos rápidos e confiáveis que contribuam para o reaproveitamento desses materiais, com ênfase nos polímeros. A identificação e classificação de materiais poliméricos por LIBS é uma tarefa desafiadora, devido a alguns fatores como: (i) composição química similar; (ii) os FR podem ser adicionados em diferentes concentrações; (iii) em alguns casos os polímeros são misturados para formarem as blendas; (iv) a grande variedade de polímeros encontradas no REEE (até 15 tipos diferentes), sendo os mais comuns, o acrinolitrila-butadieno-estireno (ABS), poliestireno (PS), polietileno (PE), policarbonato (PC), poliamida (PA), polipropileno (PP) e as blendas constituídas por PC/ABS. 5,277

Alguns grupos de pesquisa têm contornado esses desafios usando ferramentas quimiométricas para a interpretação dos dados, e os resultados têm sido promissores. Muitos trabalhos têm demonstrado que é possível usar todo o espectro LIBS associado às ferramentas quimiométricas, a fim de identificar e classificar diferentes polímeros. ${ }^{5}$

Um dos primeiros trabalhos na análise de polímeros por LIBS foi proposto por Sattman et al. ${ }^{278}$ Nesse trabalho, os autores combinaram as ANN com os espectros LIBS para discriminar com exatidão PP, PE, polietileno tereftalato (PET) e o policloreto de polivinila (PVC). Em trabalho proposto por Anzano et al. ${ }^{279}$ cinco tipos de polímeros foram discriminados usando apenas a correlação entre os espectros LIBS. Nesse sentido, Lasheras et al. ${ }^{280}$ usaram o espectro LIBS associado ao methods of normalized coordinates (MNC) para a identificação de 11 polímeros de diferentes composições químicas. Já Unnikrishnan et al. ${ }^{281}$ usaram diferentes regiões dos espectros LIBS associadas a PCA para classificar quatro diferentes tipos de polímeros. Aquino 
e Pereira-Filho ${ }^{282}$ analisaram polímeros provenientes de carcaça de celular e usaram as ferramentas quimiométricas SIMCA, KNN e PLS-DA para propor modelos de classificação, a fim de identificar as amostras a partir do fabricante e país de origem.

No entanto, em alguns casos, os polímeros não podem ser identificados diretamente apenas observando o espectro original da LIBS. Assim, são necessárias informações sobre a emissão de bandas moleculares e a razão das mesmas com linhas de emissão de um dado elemento da constituição original do polímero. Essa estratégia foi proposta inicialmente por Anzano et al., para identificação qualitativa PET, PS e PVC, e posteriormente foi aprimorada por outros grupos de pesquisas. ${ }^{283-285}$ De acordo Grégoire et al. ${ }^{286}$ é possível distinguir os polímeros aromáticos (PS e PC) dos polímeros alifáticos (PE, PP e $\mathrm{PA})$, usando somente as linhas e banda de emissão $\left(\mathrm{C}_{2}, \mathrm{CN}, \mathrm{H}, \mathrm{C}, \mathrm{N}\right.$ e $\mathrm{O})$, e as razões entre linhas de emissão e banda molecular $\left(\mathrm{H} / \mathrm{C}_{2}, \mathrm{H} / \mathrm{C}\right.$ and $\mathrm{O} / \mathrm{N})$. Em trabalho proposto por Costa et al. ${ }^{44}$ diferentes razões entre linhas de emissão e bandas moleculares $\left(\mathrm{C} / \mathrm{H}, \mathrm{C} / \mathrm{C}_{2}, \mathrm{C} / \mathrm{N}, \mathrm{C} / \mathrm{O}\right.$, $\mathrm{H} / \mathrm{C}_{2}, \mathrm{H} / \mathrm{N}, \mathrm{H} / \mathrm{O}, \mathrm{C}_{2} / \mathrm{N}, \mathrm{C}_{2} / \mathrm{O}$ e $\left.\mathrm{O} / \mathrm{N}\right)$ foram usadas para identificar seis polímeros (ABS, PS, PC, PE, PP e PA). Modelos de classificação KNN e SIMCA foram usados para classificação. Ambos os modelos apresentaram resultados satisfatórios, com exatidão de $98 \%$ e $92 \%$ para o KNN e SIMCA, respectivamente. Adicionalmente, 15 amostras de polímeros desconhecidas foram analisadas pelos modelos propostos e pela técnica de referência differential scanning calorimetry (DSC), e os resultados apresentados pelos modelos SIMCA e KNN estavam coerentes com aqueles obtidos pelo DSC.

Um estudo recente ampliou as potencialidades da LIBS, para além da identificação e classificação de polímeros. Em trabalho proposto por Costa et al..$^{287}$ um novo método de análise direta por LIBS, para quantificação de PC e ABS em suas blendas (PC/ABS), foi aplicado com sucesso. Inicialmente, foram construídos modelos de calibração multivariada usando PLS. Os modelos PLS foram obtidos a partir de um conjunto de 11 padrões com diferentes concentrações de $\mathrm{PC} /$ ABS (m/m\%). O método proposto foi aplicado em 33 amostras de $\mathrm{PC} / \mathrm{ABS}$ provenientes de diferentes equipamentos eletrônicos. Adicionalmente, as amostras também foram analisadas por técnica de referência usando a DSC e os resultados apresentados corroboraram aqueles previstos pelos modelos PLS. A fim de avaliar a robustez dos modelos, amostras de PE, PP e PS também foram analisadas. O objetivo foi avaliar se os modelos eram sensíveis para descriminar outras amostras que não fossem PC/ABS. Os modelos PLS previram valores inconsistentes variando de -19 a $171 \mathrm{~m} / \mathrm{m} \%$. Assim, os modelos propostos mostraram-se robustos e eficientes.

Além da identificação de polímeros e da quantificação de constituintes em blendas poliméricas, alguns trabalhos têm usado a LIBS para determinar FR principalmente a base de Sb. Nesse sentido, Aquino et al. ${ }^{129}$ propuseram um novo método para determinação de Sb em blendas de PC/ABS. Como estratégia de calibração, os autores usaram a adição de padrão, na qual o Sb foi incorporado nos padrões de PC/ABS. A faixa de concentração do Sb encontrada nas amostras variou de 0,15 a $0,68 \% \mathrm{~m} / \mathrm{m}$. Testes de adição de padrão foram realizados e as recuperações variaram de 63 a $83 \%$. Recentemente, Lazic et al. ${ }^{288}$ usaram LIBS para determinar Sb em diversos materiais plásticos. Como estratégia de calibração foi adotada a compatibilização de matriz e um conjunto de amostras com concentrações conhecidas. A faixa de concentração encontrada nas amostras variou entre 0,14 a $6,5 \% \mathrm{~m} / \mathrm{m}$.

Como informado anteriormente, a LIBS também é usada para análise de PCB e alguns trabalhos têm sido desenvolvidos nesse sentido. Recentemente, Sperança et al. ${ }^{169}$ usaram a LIBS para analisar diretamente as máscaras de solda tipicamente comercializadas para produção caseira de PCB. Carvalho et al. ${ }^{53}$ propuseram uma estratégia combinando LIBS e PCA para investigar a distribuição de 18 metais nas $\mathrm{PCB}$ provenientes de celular usando imagens hiperespectrais. Esse campo LIBS e PCB ainda é pouco explorado, no entanto a LIBS já tem se mostrado como uma poderosa ferramenta para rápida inspeção química nesses tipos de amostras.

\section{PERSPECTIVAS FUTURAS E CONCLUSÃO}

A LIBS tem se desenvolvido rapidamente nos últimos anos e está se consolidando entre as técnicas modernas de espectrometria atômica. As referências bibliográficas citadas nesta revisão permitem observar os diversos campos de aplicação da técnica. Vale ressaltar que as aplicações da LIBS não estão restritas apenas às que foram apresentadas nesta revisão, e outras áreas como o patrimônio cultural, ${ }^{289}$ geoquímica, ${ }^{290}$ estudos de materiais não terrestre ${ }^{291}$ e arqueo-

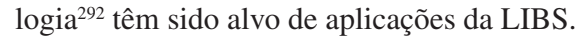

Ainda há diversos pontos específicos que devem ser aprimorados, principalmente no que diz respeito ao aumento da sensibilidade. Nesse sentido, já existem diversas propostas principalmente empregando estratégias de pré-concentração, e também destacamos a utilização de nanopartículas para o aumento da sensibilidade em LIBS, cuja primeira revisão foi publicada em 2018 por Dell'Aglio et al. ${ }^{293} \mathrm{Em}$ relação às análises quantitativas, diversos avanços podem ser notados, principalmente no desenvolvimento de novas estratégias de calibração menos susceptíveis aos efeitos de matriz.

Como já destacado neste texto, umas das características muito atraentes da LIBS é a possibilidade de analise in situ e, com esse objetivo, nos últimos anos diversas propostas de equipamentos portáteis foram desenvolvidas com sucesso, mostrando que o futuro da técnica caminha para a expansão das análises in situ. Além disso, já existem novas tecnologias para desenvolvimentos de sistema em linhas em processos industriais principalmente para análise de materiais recicláveis e plásticos. ${ }^{294}$

A combinação da LIBS com outras técnicas analíticas pode trazer resultados que se complementam, permitindo a obtenção de informações mais precisas e exatas. Também é possível notar que a LIBS e a quimiometria caminham cada vez mais juntas, e a tendência para os próximos anos é que as ferramentas quimiométricas consolidem-se entre os grupos de pesquisa que utilizam a LIBS. Por fim, esperamos que essa revisão sirva de material base para os interessados na análise direta de amostras sólidas por LIBS. Além disso, acreditamos que esse material será útil para introduzir conceitos de LIBS em cursos de graduação, apresentando as potencialidades da técnica. Nos cursos de graduação esses conceitos poderiam ser apresentados em disciplinas de análise instrumental.

\section{AGRADECIMENTOS}

Os autores agradecem à Fundação de Amparo à Pesquisa do Estado de São Paulo (FAPESP, bolsas 2014/11415-0, 2016/015130, 2016/17304-0 e 2016/17221-8), Conselho Nacional de Desenvolvimento Científico e Tecnológico (CNPq, 401074/2014-5, 305637/2015-0, 141311/2017-7, 150517/2017-0 e 160152/2015-1), ao Programa Nacional de Bolsas de Pós-Doutorado (PNPD) e a Coordenação de Aperfeiçoamento de Pessoal de Nível Superior Brasil (CAPES) - Código de Financiamento 001.

\section{REFERÊNCIAS}

1. Zagatto, E. A. G.; Sá, S. M. O.; J. Braz. Chem. Soc. 2003, 14, 153.

2. Rocha, F. R. P.; Pereira-Filho, E. R.; Nóbrega, J. A.; J. Braz. Chem. Soc. 2009, 20, 1759 .

3. Reisch, M. S.; Chem. Eng. News 2018, 26, 20.

4. Nascentes, C. C.; Korn, M. G. A.; Zanoni, M. V. B.; Quim. Nova 2017, $6,643$. 
5. Costa, V. C.; Castro, J. P.; Andrade, D. F.; Babos, D. V.; Garcia, J. A.; Sperança, M. A.; Catelani, T. A.; Pereira-Filho, E. R.; Trends Analyt. Chem. 2018, 108, 65.

6. Einstein, A.; Phys. Z. 1917, 18, 121.

7. Cremers, D. A.; Radziemski, L. J.; Handbook of Laser-Induced Breakdown Spectroscopy. Ed. John Wiley \& Sons Ltd: Chichester, 2006. 302p.

8. Maiman, T. H.; Nature, 1960, 187, 493.

9. Javan, A.; Bennett, W. R.; Herriott, D. R.; Phys. Rev. Lett. 1961, 6, 106.

10. Geusic, J. E.; Marcos, H. M.; Van Uitert, L. G.; Phys. Lett. 1964, 4, 182.

11. Brech, F.; Cross, L.; Appl. Spectrosc. 1962, 16, 59.

12. Debras-Guedon, J.; Liodec, N.; C. R. Acad. Sci. 1963, 257, 3336.

13. Maker, P. D.; Terhune, R. W.; Savage, C. M.; Proceedings of Third International Conference on Quantum Electronics, Paris, France, 1964.

14. Runge, E. R.; Minck, R. W.; Bryan, F. R.; Spectrochim. Acta, Part B 1964, 20, 733 .

15. Zel'dovich, Y. B.; Raizer, Y. P.; Soviet Physics 1965, 20, 772.

16. Moenke, H.; Moenke-Blankenburg, L.; Laser MicroSpectrochemical Analysis, Crane, Russak \& Co: New York, 1973, cap. 2.

17. Young, M.; Hercher, M.; Yu, C. Y.; Appl. Phys. 1966, 37, 4938.

18. Radziemski, L. J.; Spectrochim. Acta, Part B 2002, 57, 1109.

19. Radziemski, L. J.; Loree, T. R.; Cremers, D. A.; Hoffman, N. M.; Anal. Chem. 1983, 55, 1246.

20. Baudelet, M.; Smith, B. W.; J. Anal. At. Spectrom. 2013, 28, 624.

21. Moenke-Blankenburg, L.; Schumann, T.; Nolte, J.; J. Anal. At. Spectrom. 1994, 9, 1059.

22. Russo, R. E.; Mao, X. L.; Liu, H. C.; Gonzalez, J.; Mao, S. S.; Talanta 2002, 57,425 .

23. Dong, M; Oropeza, D.; Chirinos, J.; Gonzalez, J. J.; Lu, J.; Mao, X.; Russo, R. E.; Spectrochim. Acta, Part B 2015, 109, 44.

24. Bonta, M.; Gonzalez, J. J.; Quarles Jr, C. D., Russo, R. R.; Hegedus, B.; Limbeck, A.; J. Anal. At. Spectrom. 2016, 31, 252.

25. Pasquini, C.; Cortez, J.; Silva, L. M. C.; Gonzaga, F. B.; J. Braz. Chem. Soc. 2007, 18, 463.

26. Cremers, D. A.; Radziemski, L. J.; Handbook of Laser-Induced Breakdown Spectroscopy, $2^{\text {nd }}$ ed., 2013.

27. Noll, R.; Laser-Induced Breakdown Spectroscopy. Fundamentals and Applications, Springer: Aachen, 2012.

28. Musazzi, S., Perini, U.; Laser-Induced Breakdown Spectroscopy theory and applications, Springer Verlag: Berlin-Heidelberg, 2014, 565 p.

29. Holler, J.; Skoog, D. A.; Crouch, S. R.; Princípios de Análise Instrumental, $6^{\text {a }}$ ed., Ed. Bookman: Porto Alegre, 2009.

30. Singh, J.; Thakur, S. N.; Laser-Induced Breakdown Spectroscopy, Elsevier: Germany, 2007.

31. Svelto, O.; Principles of Lasers, $5^{\text {th }}$ ed., Springer: New York, 2010.

32. Demtröder, W; Laser Spectroscopy. Vol. 1: Basic Principles, $4^{\text {th }}$ ed., Ed. Springer: Berlim, 2008, 235p.

33. Chichkov, B. N.; Momma, C.; Nolte, S.; Von Alvensleben, F.; Tunnermann. A.; Appl. Phys. A. Mater. Sci. Process. 1996, 63, 109.

34. Labutin, T. A.; Ledned, V. N.; Ilyin, A. A.; Popov, A. M.; J. Anal. At. Spectrom., 2016, 31, 90.

35. Telle, H. H.; Ureña, A. G.; Donovan, R. J.; Laser chemistry: spectroscopy, dynamics and applications, John Wiley \& Sons Ltd: Chichester, 2007, 156p.

36. Miziolek, A. W.; Palleschi, V.; Schechter, I.; Laser-Induced Breakdown Spectroscopy (LIBS): Fundamentals and Applications, Cambridge University Press: New York, 2006.

37. Bauer, H. E.; Leis, F.; Niemax, K.; Spectrochim. Acta, Part B 1998, 53, 1815.

38. Haisch, C.; Panne, U.; Niessner, R.; Spectrochim. Acta, Part B 1998, 53, 1657.

39. Jantzi, S. C.; Motto-Ros, V.; Trichard, F.; Markushin, Y.; Melikechi, N.; De Giacomo, A.; Spectrochim. Acta, Part B 2016, 115, 52.
40. Krug, F. J.; Rocha, F. R. P.; Métodos de preparo de amostras. Fundamentos sobre o preparo de amostras orgânicas e inorgânicas para análise elementar, EditSBQ: São Paulo, 2016.

41. Jull, H.; Kunnemeyer, R.; Schaare, P.; Precision Agriculture 2018, 19, 823.

42. Cahoon, E. M.; Almirall, J. R.; Appl. Opt. 2010, 49, 49.

43. Castro, J. P; Pereira-Filho, E. R.; J. Anal. At. Spectrom. 2016, 31, 2005.

44. Costa, V. C.; Aquino, F. W. B.; Paranhos, C. M.; Pereira-Filho, E. R.; Polym. Test. 2017, 59, 390.

45. Sperança, M. A.; Aquino, F. W. B.; Fernandes, M. A.; Lopez-Castillo, A.; Carneiro, R. L.; Pereira-Filho, E. R.; Geostand. Geoanal. Res. 2016, $41,273$.

46. Figueiredo, C. M.; Castro, J. P.; Sperança, M. A.; Fialho, L. L.; Nóbrega, J. A.; Pereira-Filho, E. R.; J. Braz. Chem. Soc. 2018, 29, 680.

47. Babos, D. V.; Virgilio, A.; Costa, V. C.; Donati, G. L.; Pereira-Filho, E. R.; J. Anal. At. Spectrom. 2018, 33, 1753.

48. Costa, V. C.; Amorim, F. A. C.; Babos, D. V.; Pereira-Filho, E. R.; Food Chem. 2019, 273, 91.

49. Augusto, A. S.; Barsanelli, P. L.; Pereira, F. M. V.; Pereira-Filho, E. R.; Food Res. Int. 2017, 94, 72.

50. Santos, Jr. D.; Nunes, L. C.; Trevizan, L. C.; Godoi, Q.; Leme, F. O.; Braga, J. W. B.; Krug, F. J.; Spectrochim. Acta, Part B 2009, 64, 1073.

51. Gondal, M. A.; Hussain, T.; Yarnani, Z. H.; Baig, M. A.; Talanta 2007, $72,642$.

52. Peruchi, L. C.; Nunes, L. C.; Carvalho, G. G. A.; Guerra, M. B. B.; Almeida, E.; Rufini, I. A.; Santos, D.; Krug, F. J.; Spectrochim. Acta, Part B 2014, 100, 129.

53. Carvalho, R. R. V.; Coelho, J. A. O.; Santos, J. M.; Aquino, F. W. B.; Carneiro, R. L.; Pereira-Filho, E. R.; Talanta 2015, 134, 278.

54. Silva, M. J.; Cortez, J.; Pasquini, C.; Honorato, R. S.; Paim, A. P. S.; Pimentel, M. F.; J. Braz. Chem. Soc. 2009, 20, 1887.

55. Harun, H. A.; Zainal, R.; J. Nonlinear Opt. Phys. Mater. 2018, 27, 1850023.

56. Sobral, H.; Sanginés, R.; Trujillo-Vázquez, A.; Spectrochim. Acta, Part B 2012, 78, 62 .

57. Lee, D. H.; Han, S. C.; Kim, T. H.; Yun, J. I.; Anal. Chem. 2011, 83, 9456.

58. Sarkar, A.; Aggarwal, S. K.; Alamelu, D.; Anal. Methods. 2010, 2, 32.

59. Yang, X.; Hao, Z.; Li, C.; Li, J.; Yi, R.; Shen, M.; Li, K.; Guo, L.; Li, X.; Lu, Y.; Opt. Express 2016, 24, 13410.

60. Yaroshchyk, P.; Morrison, R. J.; Body, D.; Chadwick, B. L.; Spectrochim. Acta, Part B 2005, 60, 986.

61. Terán, E.J; Montes, M. L.; Rodríguez, C.; Martino, L.; Quiroga, M.; Landa, R.; Torres Sánchez, R. M.; Días Pace, D. M.; Microchem. J. 2019, 144, 159.

62. Papai, R.; Sato, R. H.; Nunes, L. H.; Krug, F. J.; Gaubeur, I.; Anal. Chem. 2017, 89, 2807.

63. Lin, Q.; Han, X.; Wang, J.; Wei, Z.; Liu, K.; Duan, Y.; J. Anal. At. Spectrom. 2016, 31, 1622

64. Andrade, D. F.; Sperança, M. A.; Pereira-Filho, E. R.; Anal. Methods 2017, 9, 5156

65. Sperança, M. A.; Andrade, D. F.; Castro, J. P.; Pereira-Filho, E. R.; Opt Laser Technol. 2019, 109, 648.

66. Hohreiter, V.; Hahn, D. W.; Anal. Chem. 2005, 77, 1118.

67. Sturm, V.; Noll, R.; Appl. Opt. 2003, 42, 6221.

68. Zhang, T.; Tang, H.; Li, H.; J. Chemom. 2018, 11, 2983.

69. Novaes, C. G.; Yamaki, R. T.; De Paula, V. F.; Júnior, B. B. N.; Barreto, J. A.; Valasques, G. S.; Bezerra, M. A.; Rev. Virtual Quim. 2017, 9, 1184.

70. Moncayo, S.; Manzoor, S.; Navarro-Villoslada, F.; Caceres, J. O.; Chemom. Intell. Lab. Syst. 2015, 146, 354.

71. Tognoni, E.; Cristoforetti, G.; Opt. Laser Technol. 2016, 79, 164.

72. Porizka, P.; Klus, J.; Hrdlicka, A.; Vrábel, J.; Skarková, P.; Prochazka, D.; Novotný, J.; Novotný, K.; Kaiser, J.; J. Anal. At. Spectrom. 2017, 32, 277. 
73. Bro, R.; Smilde, A. K.; Anal. Methods. 2014, 6, 2812.

74. Porizka, P.; Klus, J.; Képes, E.; Prochazka, D.; Hahn, D. W.; Kaiser, J.; Spectrochim. Acta, Part B 2018, 148, 65.

75. Bezerra, M. A.; Ferreira, S. L. C.; Novaes, C. G.; Santos, A. M. P.; Valasques, G. S.; Cerqueira, U. M. F. M.; Alves, J. P. S.; Talanta 2019, 194, 941.

76. Pereira, F. M. V.; Pereira-Filho, E. R.; Quim. Nova 2018, 41, 1061.

77. Novaes, C. G.; Yamaki, R. T.; Nascimento, Jr. B. B.; Barreto, J. A.; Valasques, G. S.; Bezerra, M. A.; Rev. Virtual Quim. 2018, 10, 393.

78. Passari, L. M. Z. G.; Soares, P. K.; Bruns, R. R.; Quim. Nova 2011, 34, 888.

79. Pimentel, M. F.; Barros-Neto, B.; Quim. Nova 1996, 19, 268.

80. Fortunato, F. M.; Catelani, T. A.; Alfonso, M. S. P.; Pereira-Filho, E. R.; Anal. Sci. 2018. doi: 10.2116/analsci.18P286

81. Andrade, D. F.; Pereira-Filho, E. R.; Konieczynski, P.; J. Braz. Chem. Soc. 2017, 28, 838.

82. Nunes, L. C.; Da Silva, G. A.; Trevizan, L. C.; Santos Jr, D.; Poppi, R. J.; Krug, J. F.; Spectrochim. Acta, Part B 2009, 64, 565.

83. Nunes, L. C.; Braga, J. W. B.; Trevizan, L. C.; Souza, P. F.; Carvalho, G. G. A.; Santos Jr, D.; Poppi, R. J.; Krug, F. J.; J. Anal. At. Spectrom. 2010, 25, 1453.

84. Ferreira, E. C.; Anzano, J. M.; Milori, D. M. B. P.; Ferreira, E. J.; Lasheras, R. J.; Bonilla, B.; Montullibor, B.; Casas, J.; Martin-Neto, L.; Appl. Spectrosc. 2009, 63, 1081.

85. Andrade, D. F.; Pereira-Filho, E. R.; J. Agric. Food. Chem. 2016, 64, 7890.

86. Neiva, A. M.; Chagas, M. A. J.; Mello, M. A.; Esteves, S. N.; PereiraFilho, E. R.; RSC Adv. 2016, 6, 104827.

87. Augusto, A. S.; Batista, E. F.; Pereira-Filho, E. R.; Anal. Methods 2016, 8,5851 .

88. Borba, F. S. L.; Cortez, J.; Asfora, V. K.; Pasquini, C.; Pimentel, M. F.; Pessise, A. M.; Khoury, H. J.; J. Braz. Chem. Soc. 2012, 23, 958.

89. Yang, J. H.; Yoh, J. J.; Appl. Spectrosc. 2018, 72, 1047.

90. Harmon, R. S.; Russo, R. E.; Hark, R. R.; Spectrochim. Acta, Part B 2013, 87, 11.

91. Guedes, W. N.; Pereira, F. M. V.; Microchem. J. 2018, 143, 331.

92. Chen, X.; Li, X.; Yu, X.; Chen, D.; Liu, A.; Spectrochim. Acta, Part B 2018, 139, 63 .

93. Li, X.; Yang, S.; Fan, R.; Yu, X.; Chen, D.; Opt. Laser Technol. 2018, $102,233$.

94. Neiva, A. M.; Sperança, M. A.; Costa, V. C.; Chagas, M. A. J.; PereiraFilho, E. R.; Environ. Monit. Assess. 2018, 190, 618.

95. Andrade, D. F.; Guedes, W. N.; Pereira, F. M. V.; Microchem. J. 2018, $137,443$.

96. Santos, M. C.; Dai, C.; Pereira, F. M. V.; J. Appl. Spectrosc. 2018, 85, 543.

97. Peña-Icart, M.; Pomares-Alfonso, M. S.; Aquino, F. W. B.; AlonsoHernandez, C.; Bolaños-Alvarez, Y.; Pereira-Filho, E. R.; Anal. Methods 2017, 9, 3713 .

98. Senesi, G. S.; Romano, R. A.; Marangoni, B. S.; Nicolodelli, G.; VillasBoas, P. R.; Benites, V. M.; Milori, D. M. B. P.; J. Appl. Spectrosc. 2017, $84,923$.

99. Zhang, T.; Chunhua, Y.; Qi, J.; Tang, H.; Li, H.; J. Anal. At. Spectrom. 2017, 32, 1960.

100. Moncayo, S.; Duponchel, L.; Mousavipak, N.; Panczer, G.; Trichard, F.; Bousquet, B.; Pelascini, F.; Motto-Ros, V.; J. Anal. At. Spectrom. 2018, 33,210 .

101. Goméz-Nubla, L.; Aramendia, J.; De Vallejuelo, S. F-O.; Madariaga, J. M.; Microchem. J. 2018, 137, 392.

102. Safi, A.; Campanella, B.; Grifoni, E.; Legnaioli, S.; Lorenzetti, G.; Pagnotta, S.; Poggialini, F.; Ripoll-Seguer, L.; Hidalgo, M.; Palleschi, V.; Spectrochim. Acta, Part B 2018, 144, 46.

103. Romera, J. P. R.; Barsanelli, P. L.; Pereira, F. M. V.; Fuel 2016, 15, 473.
104. Braga, J. W. B.; Trevizan, L. C.; Nunes, L. C.; Rufini, I. A.; Santos Jr, D.; Krug, F. J.; Spectrochim. Acta, Part B 2010, 25, 1453.

105. Delgado, T.; Vadillo, J. M.; Laserna, J. J.; J. Anal. At. Spectrom. 2018, 33,1469 .

106. Aras, N.; Yalçin, S.; J. Anal. At. Spectrom. 2014, 29, 545.

107. Marin-Roldan, A.; Manzoor, S.; Moncayo, S.; Navarro-Villoslada, F.; Izquierdo-Hornillos, R. C.; Caceres, J. O.; Spectrochim. Acta, Part B 2013, $88,186$.

108. Moncayo, S.; Trichard, F.; Busser, B.; Sabatier-Vincent, M.; Pelascini, F.; Pinel, N.; Templier, I.; Charles, J.; Sancey, L.; Motto-Ros, V.; Spectrochim. Acta, Part B 2017, 133, 40.

109. Silva, T. V.; Hubinger, S. Z.; Neto, J. A. G.; Milori, D. M. B. P.; Ferreira, E. J.; Ferreira, E.C; Spectrochim. Acta, Part B 2017, 135, 29.

110. Vieira, A. L.; Silva, T. V.; Sousa, F. S. I.; Senesi, G. S.; Santos, Jr. D.; Ferreira, E. C.; Neto, J. A. G.; Microchem. J. 2018, 139, 322.

111. Millar, S.; Gottlieb, C.; Günther, T.; Sankat, N.; Wilsch,G.; Kruschwitz, S.; Spectrochim. Acta, Part B 2018, 147, 1.

112. Zhu, Z.; Li, J.; Guo, Y.; Cheng, X.; Tang, Y.; Guo, L.; Li, X.; Lu, Y.; Zeng, X.; J. Anal. At. Spectrom. 2018, 33, 205.

113. Yao, M.; Yang, H.; Huang, L.; Chen, T.; Rao, G.; Liu, M.; Appl. Opt. 2017, 56, 4070.

114. Motto-Ros, V.; Syvilay, D.; Bassel, L.; Negre, E.; Trichard, F.; Pelaschini, F.; El Haddad, J.; Harhira, A.; Moncoyo, S.; Picard, J.; Devismes, D.; Bouquest, B.; Spectrochim. Acta, Part B 2018, 140, 56.

115. Cabalín, M.; Mateo, M. P.; Laserna J. J.; Surf. Interface Anal 2003, 35, 263.

116. Ohta, T.; Ito, M.; Kotani, T.; Hattori, T.; Appl. Spectrosc. 2009, 63, 555.

117. Dixit, Y.; Casado-Gavalda, M. P.; Cama-Moncunill, R.; CamaMoncunill, X.; Markiewicz Keszycka, M.; Jacoby, F.; Cullen, P. J.; Sullivan, C.; J. Food Eng. 2018, 216, 120.

118. Castro, J. P; Pereira-Filho, E. R.; Talanta 2018, 189, 205.

119. Syta, O.; Wagner, B.; Bulska, E.; Zielińska, D.; Żukowska, G. Z.; Gonzalez, J.; Russo, R.; Talanta 2018, 179, 784.

120. Senesi, G.S; Martin-Neto, L.; Villas-Boas, P. R.; Nicolodelli, G.; Milori, D. M. B. P.; J. Soils Sediments 2018, 18, 1292.

121. Yi, R. X.; Guo, L. B.; Zou, X. H.; Li, J. M.; Hao, Z. Q.; Yang, X. Y.; Li, X. Y.; Zeng, X. Y.; Lu, Y. F.; Opt. Express 2016, 24, 10233.

122. Carvalho, G. G. A.; Guerra, M. B. B.; Adame, A.; Nomura, C. S.; Oliveira, P. V.; Carvalho, H. W. P.; Santos Jr, D.; Nunes, L. C.; Krug, F. J.; J. Anal. At. Spectrom. 2018, 33, 919.

123. Gornushkin, I. B.; Völker, T.; Kazakov, A. Y.; Spectrochim. Acta, Part B 2018, 147, 149 .

124. Cavalcanti, G. H.; Teixeira, D. V.; Legnaioli, S.; Lorenzetti, G.; Pardini, L.; Palleschi, V.; Spectrochim. Acta, Part B 2013, 87, 51.

125. Sezer, B.; Durna, S.; Bilge, G.; Berkkan, A.; Yetisemiyen, A.; Boyaci, I. H.; Int. Dairy J. 2018, 81, 1.

126. Hernández-García, R.; Villanueva-Tagle, M. E.; Calderón-Piñar, F.; Durruthy- Rodríguez, M. D.; Aquino, F. W. B.; Pereira-Filho, E. R.; Pomares-Alfonso, M. S.; Microchem. J. 2017, 130, 21.

127. Takahashi, T.; Thornton, B.; Spectrochim. Acta, Part B 2017, 138, 31.

128. Moncayo, S.; Manzoor, S.; Rosales, J.; Anzano, J.; Caceres, J.; Food Chem. 2017, 232, 322.

129. Aquino, F. W. B.; Paranhos, C. M.; Pereira-Filho, E. R.; J. Anal. At. Spectrom. 2016, 31, 1228.

130. Carvalho, G. G. A.; Moros, J.; Santos Jr., D.; Krug, F. J.; Laserna, J. J.; Anal. Chim. Acta 2015, 876, 26.

131. Austria Jr, E. S.; Fuentes, E. M.; Nuesca, G. M.; Lamorena, R. B.; Spectrochim. Acta, Part B 2017, 136, 1.

132. Leme, F. O.; Silvestre, D. M.; Nascimento, A. N.; Nomura, C. S.; J. Anal. At. Spectrom. 2018, 33, 1322.

133. Shirvani-Mahdavi, H.; Shafiee, P.; Meas. Sci. Technol. 2016, 27, 125502.

134. Yao, S.; Xu, J.; Baj, K.; Lu, J.; Plasma Sci. Technol. 2015, 938.

135. Morais, C. P.; Barros, A. I.; Santos Jr, D.; Ribeiro, C. A.; Crespi, M. S.; 
Senesi, G. S.; Gomes-Neto, J. A.; Ferreira, E. C.; Microchem. J. 2017, 134, 370.

136. Sperança, M. A.; Pomares-Afonso, Pereira-Filho, E. R.; Anal. Methods 2018, 10, 533 .

137. Carvalho, A. A. C.; Leme, F. O.; Luz, M. S.; Oliveira, P. V.; Nomura, C. S.; J. Anal. At. Spectrom. 2018, 33, 1243.

138. Ciucci, A.; Corsi, M.; Palleschi, V.; Rastelli, S.; Salvetti, A.; Tognoni, E.; Appl. Spectrosc. 1999, 53, 960.

139. Tognoni, E.; Cristoforetti, G.; Legnaioli, S.; Palleschi, V.; Spectrochim. Acta, Part B 2010, 65, 1 .

140. Davari, S. A.; Hu, S.; Mukherjee, D.; Talanta 2017, 164, 330.

141. Suchonová, M.; Kristof, J.; Pribula, M.; Veis, M., Tabarés, F. L.; Veis, P.; Fusion Eng. Des. 2017, 117, 175.

142. Augusto, A. S.; Castro, J. P.; Sperança, M. A.; Pereira-Filho, E. R.; J. Braz. Chem. Soc. 2019, 30, 804.

143. Peng, J.; Liu, F.; Zhou, F.; Song, K.; Zhang, C.; Ye, L.; He, Y.; TrAC Trends Anal. Chem. 2016, 85, 260.

144. Sezer, B.; Bilge, G.; Boyaci, I. H.; TrAC - Trends Anal. Chem. 2017, 97, 345.

145. Yu, X.; Li, Y.; Gu, Yang.; Bao, J.; Yang, H.; Sun, L.; Environ. Monit. Assess., 2014, 186, 8969.

146. Kaiser, J.; Novotny, K.; Martin, M. Z.; Hrdlicka, A.; Malina, R.; Hartl, M.; Adam, V.; Kizek, R.; Surf. Sci. Rep. 2012, 67, 233.

147. Busser, B.; Moncayo, S.; Coll, J. L.; Sancey, L.; Motto-Ros, V.; Coord. Chem. Rev. 2018, 358, 70.

148. Galbács, G.; Anal. Bioanal. Chem. 2015, 407, 7537.

149. Noll, R.; Fricke-Begemann, C.; Connemann, S.; Meinhardt, C.; Sturm, V.; J. Anal. At. Spectrom., 2018, 33, 945.

150. Nicolodelli, G.; Senesi, G. S.; Perazzoli, I. L. O.; Marangoni, B. S.; Benites, V. M.; Milori, D. M. B. P.; Sci. Total Environ., 2016, 565, 1116.

151. Tadini, A. M.; Nicolodelli, G.; Senesi, G. S.; Ishida, D. A.; Montes, C. R.; Lucas, Y.; Mounier, S.; Guimaraes, F. E. G.; Milori, D. M. B. P.; Sci. Total Environ. 2018, 613-614, 160.

152. Gondal, M. A.; Habibullah,Y. B.; Baig, U.; Oloore, L. E.; Talanta 2016, $152,341$.

153. Yang, P.; Zhou, R.; Zhang, W.; Yi, R.; Tang, S.; Guo, L.; Hao, Z.; Li, X.; Lu, Y.; Zeng, X.; Food Chem. 2019, 272, 323.

154. Temiz, H. T.; Sezer, B.; Berkkan, A.; Tamer, U.; Boyaci, I. H.; J. Food Compost. Anal. 2018, 67, 48.

155. Gaubeur, I.; Aguirre, M. A.; Kovachev, N.; Hidalgo, M.; Canals, A.; J. Anal. At. Spectrom. 2015, 30, 25.

156. Akhtar, M.; Jabbar, A.; Mehmood, S.; Ahmeda, N.; Ahmeda, R.; Baiga, M. A.; Spectrochim. Acta, Part B 2018, 148, 143.

157. Almessiere, M. A.; Altuwiriqi, R.; Gondal, M. A.; AlDakheel, R. K.; Alotai, H. F.; Talanta 2018, 185, 61.

158. Chen, X.; Li, X. H.; Yang, S. B.; Yu, X.; Liu, A. C.; Biomed. Opt. Express 2018, 9, 1057.

159. Carvalho, G. G. A.; Nunes, L. C.; Souza, P. F.; Krug, F. J.; Alegre, T. C.; Santos, D.; J. Anal. At. Spectrom. 2010, 25, 803.

160. Jesus, A. M. D.; Aguirre, M. A.; Hidalgo, M.; Canals, A.; Pereira, E. R.; J. Anal. At. Spectrom. 2014, 29, 1813.

161. Myakalwar, A. K.; Sreedhar, S.; Barman, I.; Dingari, N. C.; Rao, S. V.; Kiran, P. P.; Tewari, S. P.; Kumar, G. M.; Talanta 2011, 87, 53.

162. Abdel-Salam, Z.; Abdelghany, S.; Harith, M. A.; Food Anal. Methods 2017, 10, 2422.

163. Lucia, F. C.; Gottfried, J. L.; Appl. Opt. 2012, 51, B83.

164. Kolmhofer, P. J.; Eschlbock-Fuchs, S.; Huber, N.; Rossler, R.; Heitz, J.; Pedarnig, J. D.; Spectrochim. Acta, Part B 2015, 106, 67.

165. Aragon, C.; Aguilera, J. A.; Anal. Chim. Acta 2018, 1009, 12.

166. Luna, A. S.; Gonzaga, F. B.; Rocha, W. F. C.; Lima, I. C. A.; Spectrom. Acta, Part B 2018, 139, 20.

167. Godoi, Q.; Santos Jr, D.; Nunes, L. C.; Leme, F. O.; Rufini, I. A.; Agnelli, J. A. M.; Trevizan, L. C.; Krug, F. J.; Spectrochim. Acta, Part B
2009, 64, 573

168. Lazic, V.; Filella, M.; Turner, A.; J. Anal. At. Spectrom. 2018, 33, 1917.

169. Sperança, M. A.; Virgílio, A.; Pereira-Filho, E. R.; Aquino, F. W. B.; Appl. Spectrosc. 2018, 72, 1205.

170. Nicolodelli, G.; Senesi, G. S.; Ranulfi, A. C.; Marangoni, B. S.; Watanabe, A.; Benites, V. M.; Oliveira, P. P. A.; Villas-Boas, P.; Milori, D. M. B. P.; Microchem. J. 2017, 133, 272.

171. Trevizan, L. C.; Santos Jr, D.; Samad, R. E.; Vieira Jr, N. D.; Nomura, C. S.; Nunes, L. C.; Rufini, I. A.; Krug, F. J.; Spectrochim. Acta, Part B 2008, 63, 1151.

172. Trevizan, L. C.; Santos Jr, D.; Samad, R. E.; Vieira Jr, N. D.; Nomura, C. S.; Nunes, L. C.; Rufini, I. A.; Krug, F. J.; Spectrochim. Acta, Part B 2009, 64, 639 .

173. Carvalho, G. G. A.; Santos Jr. D.; Nunes, L. C.; Gomes, M. S.; Leme, F. O.; Krug, F. J.; Spectrochim. Acta, Part B 2012, 74-75, 162.

174. Gomes, M. S.; Carvalho, G. G. A.; Santos Jr, D.; Krug, F. J.; Spectrochim. Acta, Part B 2013, 86, 137.

175. Souza, P. F.; Santos Jr, D.; Carvalho, G. G. A.; Nunes, L. C.; Gomes, M. S.; Guerra, M. B. B.; Krug, F. J.; Spectrochim. Acta, Part B 2013, 83-84, 61.

176. Carvalho, G. G. A.; Santos Jr. D.; Gomes, M. S.; Nunes, L. C.; Guerra, M. B. B.; Krug, F. J.; Spectrochim. Acta, Part B 2015, 105, 130.

177. Silvestre, D. M.; Barbosa, F. M.; Aguiar, B. T.; Leme, F. O.; Nomura, C. S.; Anal. Chem. Res. 2015, 5, 28.

178. Shukla, P.; Kumar, R.; Raib, A. K.; J. Appl. Spectrosc. 2016, 83, 872.

179. Santos, D.; Nunes, L. C.; Carvalho, G. G. A.; Gomes, M. S.; Souza, P. F.; Leme, F. O.; Santos, L. G. C.; Krug, F. J.; Spectrochim. Acta, Part B 2012, 71-72, 3 .

180. Pereira, F. M. V.; Milori, D. M. B. P.; Venâncio, A. L.; Russo, M. S. T.; Martins, P. K.; Freitas-Astúa, J.; Talanta 2010, 15, 351.

181. Ranulfi, A. C.; Romano, R. A.; Magalhães, A. B.; Ferreira, E. J.; VillasBoas, P. R.; Milori, D. M. B. P.; Appl. Spectrosc. 2017, 71, 1471.

182. Ranulfi, A. C.; Senesi, G. S.; Caetano, J. B.; Meyer, M. C.; Magalhães, A. B.; Vilas-Boas, P. R.; Milori, D. M. B. P.; Microchem. J. 2018, 141, 118.

183. Krajcarova, L.; Novotny, K.; Kummerova M.; Dubova, J.; Gloser, V.; Kaiser, J. Talanta 2017, 173, 28.

184. Krystofova, O.; Shestivska, V.; Galiova, M.; Novotny, K.; Kaiser, J.; Zehnalek, J.; Babula, P.; Opatrilova, R.; Adam, V.; Kizek, R.; Sensors 2009, 9, 5040 .

185. Guerra, M. B. B.; Adame, A.; Almeida, E.; Carvalho, G. G. A.; Brasil, M. A. S.; Santos Jr, D.; Krug, F. J.; J. Anal. At. Spectrom. 2015, 30, 1646.

186. Nunes, L. C.; Carvalho, G. G. A.; Santos Jr, D.; Krug, F. J.; Spectrochim. Acta, Part B 2014, 97, 42.

187. Marangoni, B. S.; Silva, K. S. G.; Nicolodelli, G.; Senesi, G. S.; Cabral, J. S.; Villas-Boas, P. R.; Texeira, C. S. S.; Nogueira, A. R. A.; Benites, V. M.; Milori, D. M. B. P.; Anal. Methods 2016, 8, 78.

188. Sha, W.; Niu, P.; Zhen, C.; Lu, C.; Jiang, Y.; J. Appl. Spectrosc. 2018, 85,653

189. Morais, C. P.; Barros, A. I.; Bechlin, M. A.; Silva, T. V.; Santos Jr, D.; Senesi, G. S.; Crespi. M. S.; Ribeiro, C. A.; Neto, J. A. G.; Ferreira, E. C.; Talanta 2018, 188, 199.

190. Burakov, V. S.; Raikov, S. N.; Tarasenko, N. V.; Belkov, M. V.; Kiris, V. V.; J. Appl. Spectrosc. 2010, 77, 595.

191. Senesi, G. S.; Senesi, N.; Anal. Chim. Acta 2016, 938, 7.

192. Ferreira, E. C.; Milori, D. M. B. P.; Ferreira, E. J.; Silva, R. M.; MartinNeto, L.; Spectrochim. Acta, Part B 2008, 63, 1216.

193. Ferreira, E. C.; Milori, D. M. B. P.; Ferreira, E. J.; Santos, L. M.; MartinNeto, L.; Nogueira, A. R. A.; Talanta 2011, 85, 435.

194. El Haddad, J.; Villot-Kadri, M.; Ismaël, A.; Gallou, G.; Michel, K.; Bruyère, D.; Laperche, V.; Canioni, L.; Bousquet. B.; Spectrochim. Acta, Part B 2013, 79-80, 51. 
195. Popov, A. M.; Zaytsev, S. M.; Seliverstov, I. V.; Zakuskin, A. S.; Labutin, T. A.; Spectrochim. Acta, Part B 2018, 148, 205.

196. Rühlmann, M.; Büchele, D.; Ostermann, M.; Bald, I.; Schmid, T.; Spectrochim. Acta, Part B 2018, 146, 115.

197. Zhang, G.; Song, H.; Liu, Y.; Zhao, Z.; Li, S.; Ren, Z.; Optik 2018, 165, 87.

198. Pontes, M.; Cortez, J.; Galvão, R.; Pasquini, C.; Araújo, M.; Coelho, R.; Chiba, M.; Abreu, M.; Madari, B.; Anal. Chim. Acta 2009, 642, 12.

199. Nicolodelli, G.; Marangoni, B. S.; Cabral, J. S.; Villas-Boas, P. R.; Senesi, G. S.; Santos, C. H.; Romano, R. A.; Segnini, A.; Lucas, Y.; Montes, C. R.; Milori, D. M. B. P.; Appl. Opt. 2014, 53, 2170.

200. Ferreira, E. C.; Ferreira, E. J.; Villas-Boas, P. R.; Senesi, G. S.; Carvalho, C. M.; Romano. R. A.; Martin-Neto. L.; Milori, D. M. B. P.; Spectrochim. Acta, Part B 2014, 99, 76.

201. Ferreira, E. C.; Neto, J. A. G.; Milori, D. M.; Ferreira, E. J.; Anzano, J. M.; Spectrochim. Acta, Part B 2015, 110, 96.

202. Villas-Boas, P. R.; Romano, R. A.; Franco, M. A. M.; Ferreira, E. C.; Ferreira, E. J.; Crestana, S.; Milori, D. M. B. P.; Geoderma 2016, 263, 195.

203. Tadini, A. M.; Nicolodelli, G.; Marangoni, B. S.; Mounier, S.; Montese, C. R.; Milori, D. M. B. P.; Microchem. J. 2019, 144, 454.

204. Markiewicz-Keszycka, M.; Cama-Moncunill, X.; Casado-Gavalda, M. P.; Dixit, Y.; Cama-Moncunill, R.; Cullen, P. J.; Sullivan, C.; Trends Food Sci. Technol. 2017, 65, 80.

205. Yang, P.; Zhu, Y.; Yang, X.; Li, J.; Tang, S.; Hao, Z.; Guo, L.; Li, X.; Zeng, X.; Lu, Y.; J. Cereal Sci. 2018, 80, 111.

206. Silva, T. V.; Milori, D. M. B. P.; Neto, J. A. G.; Ferreira, E. J.; Ferreira, E. C.; Food Chem. 2019, 278, 223.

207. Sezer, B.; Berkkan, G. B. A.; Aysel, G. B.; Tamer, U.; Boyaci, I. H.; Food Chem. 2018, 240, 84.

208. Markiewicz-Keszycka, M.; Casado-Gavalda, M. P.; Cama-Moncunill, X.; Cama-Moncunill, R.; Dixit, Y.; Cullen, P. J.; Sullivan, C.; Food Chem. 2018, 244, 324.

209. Costa, V. C.; Babos, D. V.; Aquino, F. W. B.; Virgílio, A.; Amorim, F. A. C.; Pereira-Filho, E. R.; Food Anal. Methods 2018, 11, 1886.

210. Wang, J.; Shi, M.; Zheng, P.; Xue, S.; Peng, R.; J. Appl. Spectrosc. 2018, 85, 190.

211. Ferreira, E. C.; Menezes, E. A.; Matos, W. O.; Milori, D. M. Nogueira, A. R. A.; Martin-Neto, L. Food Control 2010, 21, 1327.

212. Bilge, G.; Boyaci, I. H.; Eseller, K. E.; Tamer, U.; Çakir, S.; Food Chem. 2015, 181, 186.

213. Singh, J.; Kumar, R.; Awasthi, S.; Singh, V.; Rai, A. L.; Food Chem. 2017, 221, 1778.

214. Zivkovic, S.; Savovic, J.; Kuzmanovic, M.; Petrovic, J.; Momcilovic, M.; Microchem. J. 2018, 137, 410.

215. Kongbonga, Y. G. M.; Ghalila, H.; Onana, M. B.; Lakhdar, Z. B.; Food Chem. 2014, 147, 327.

216. Sezer, B.; Bilge, G.; Boyaci, I. H.; J. Agric. Food Chem. 2016, 64, 9459.

217. Bilge, G.; Sezer, B.; Eseller, K. E.; Berberoglu, H.; Koksel, H.; Boyaci, I. H.; Spectrochim. Acta, Part B 2016, 124, 74.

218. Lin, H.; Mingyin, Y.; Jinlong, L.; Muhua, L.; Xiuwen, H.; J. Appl. Spectrosc. 2014, 80, 957.

219. Ponce, L.; Flores, T.; Alvira, F.; Bilmes, G.; Sosa-Saldana, M.; Appl. Opt. 2016, 55, 254.

220. Yao, S.; Zhao, J.; Xu, J.; Lu, Z.; Lu, J.; J. Anal. At. Spectrom. 2017, 32, 766.

221. Multari, R. A.; Cremers, D. A.; Dupre, J. A. M.; Gustafson, J. E.; J. Agric. Food Chem. 2013, 61, 8687.

222. Kim, G.; Kwak, J.; Choi, J.; Park, K.; J. Agric. Food Chem. 2012, 60, 718.

223. Ma, F.; Dong, D.; Food Anal. Methods 2014, 7, 1858.

224. Huiqin, H.; Lin, H.; Muhua, L.; Tianbing, C.; Ping, Y.; Mingyin, Y.; Plasma Sci. Technol. 2015, 17, 711.
225. Bilge, G.; Velioglu, H. M.; Sezer, B.; Eseller, K. E.; Boyaci, I. H.; Meat Sci. 2016, 119, 118.

226. Casado-Gavalda, M. P.; Dixit, Y.; Geulen, D.; Cama-Moncunill, R.; Cama-Moncunill, X.; Markiewicz-Keszycka, M.; Cullen, P. J.; Sullivan, C.; Talanta 2017, 169, 123.

227. Dixit, Y.; Casado-Gavalda, M.; Cama-Moncunnil, R.; Cama-Moncunnill, X.; Markiewicz-Keszycka, M.; Cullen, P.; Sullivan, C.; Anal. Methods 2017, 9, 3314.

228. Cáceres, J. O.; Moncayo, S.; Rosales, J. D.; Villena, F. J. M.; Alvira, F. C.; Bilmes, G. M.; Appl. Spectrosc. 2013, 67, 1064.

229. Moncayo, S.; Rosales, J. D.; Izquierdo-Hornillos, R.; Anzano, J.; Cácere, J. O.; Talanta 2016, 158, 185.

230. Peña-Icart, M.; Pereira-Filho, E. R.; Filaho, L. L.; Nóbrega, J. A.; Alonso-Hernandez, C.; Bolanos-Alvarez, Y.; Pomares-Alfonso, M. S.; Chemosphere 2017, 168, 1267.

231. Carvalho, A. A. C.; Silvestre, D. M.; Leme, F. O.; Naozuka, J.; Intima, D. P.; Nomura, C. S.; Microchem. J. (2018), doi: 10.1016/j. microc.2018.08.031.

232. Ruiz, F. J.; Ripoll, L.; Hidalgo, M.; Canals, A.; Talanta 2018, 191, 162.

233. Sirven, J. B.; Bousquet, B.; Sarger, L.; Anal. Chem. 2006, 78, 1462.

234. Pandhija, S.; Rai, N. K.; Rai, A. K.; Thakur, S. N.; Appl. Phys. B. 2010 , 98, 23.

235. Mukhono, P. M.; Angeyo, K. H.; Dehayem-Kamadjeu, A.; Kaduki, K. A.; Spectrochim. Acta, Part B 2013, 8, 81.

236. Zaytsev, S. M.; Krylov, I. N.; Popov, A. M.; Zorov, N. B.; Labutin, T. A.; Spectrochim. Acta, Part B 2018, 140, 65.

237. Yi, R.; Yang, X.; Zhou, R.; Li, J.; Yu, H.; Hao, Z.; Guo, L.; Li, X.; Lu, Y.; Zeng, X.; Anal. Chem. 2018, 90, 7080.

238. Emara, E. M.; Imam, H; Hassan, M.; Elnaby, S. H.; Talanta 2013, 117 , 183.

239. Rusak, D. A.; Zeleniak, A. E.; Obuhosky, J. L.; Holdren, S. M.; Noldy, C. A.; Talanta 2013, 117, 55.

240. Grolmusova, Z.; Hornackova, M.; Plavcan, J.; Kopani, M.; Babal, P.; Veis, P.; Eur. Phys. J. Appl. Phys. 2013, 63, 20801.

241. Metzinger, A.; Kovács-Széles, E.; Almási, I.; Galbács, G.; Appl Spectrosc. 2014, 68, 789.

242. Bello, L. T.; Ana, P. A.; Santos, D.; Krug, F. J.; Zezell, D. M.; Vieira, N. D.; Samad, R. E.; Appl. Spectrosc. 2017, 71, 659.

243. Gaudiuso, R.; Ewusi-Annan, E.; Melikechi, N.; Sun, X.; Liu, B.; Campesato, L.; Merghoub, T.; Spectrochim. Acta, Part B 2018, 146, 106.

244. Putnam, R. A.; Mohaidat Q. I.; Daabous, A.; Rehse, S. J.; Spectrochim. Acta, Part B 2013, 87,161.

245. Manzoor, S.; Moncayo, S.; Navarro-Villoslada, F.; Ayala, J. A.; Izquierdo-Hornillos, R.; Villena, F. J. M.; Caceres, J. O.; Talanta 2013, 121,65 .

246. Manzoor, S.; Ugena, L.; Tornero-Lópes, J.; Martín, H.; Molina, M.; Camacho, J. J.; Cáceres, J. O.; Talanta 2016, 155, 101.

247. Davari, S. A.; Masjedi, S.; Ferdous, Z.; Mukherjee, D. J.; Biophotonics 2018, 11,1 .

248. Anzano, J.; Bonilla, B.; Montull-Ibor, B.; Casas-González, J.; Med. Chem. Res. 2009, 18, 656.

249. Tiwari, P. K.; Awasthi, S.; Kumar, R.; Anand, R. K.; Rai, P. K.; Rai, A. K.; Laser Med. Sci. 2018, 33, 263.

250. Dubey, A.; Keyvan, G.; Hsia, R.; Saranteas, K.; Brone, D.; Misra, T.; Muzzio, F. J.; J. Pharm. Innov. 2011, 6, 77.

251. Cahoon, E. M.; Almirall, J. R.; Appl. Opt. 2010, 49, C49.

252. Gottfried, J. L.; Appl. Opt. 2013, 52, B10.

253. Metzinger, A.; Rajkó, R.; Galbács, G.; Spectrochim Acta, Part B 2014, 94-95, 48.

254. Kula, A.; Wietecha-Posluszny, R.; Pasionek, K.; Krol, M.; Wozniakiewicz, M.; Koscielniak, P.; Sci Justice 2014, 54, 118.

255. Lennard, C.; El-Deftar, M. M.; Robertson, J.; Forensic. Sci. Int. 2015, 254,68 . 
256. Alvira, F. C.; Bilmes, G. M.; Flores, T.; Ponce, L.; App. Spectrosc. 2015, 69, 1205.

257. Krol, M.; Kowalska, D.; Koscielniak, P.; Anal. Lett. 2018, 51, 1592.

258. Yang, J. H.; Yoh, J. J.; Microchem. J. 2018, 139, 386.

259. Moncayo, S.; Manzoor, S.; Ugidos, T.; Navarro-Villoslada, F.; Caceres, J. O.; Spectrochim. Acta, Part B 2014, 101, 21.

260. Choi, S.; Yoh, J. J.; Spectrochim. Acta, Part B 2017, 134, 75.

261. Bhatt, B.; Angeyo, K. H.; Dehayem-Kamadjeu, A.; Anal. Methods 2018 , $10,791$.

262. Doña-Fernández, A.; Andres-Gimeno, I.; Santiago-Toribio, P.; ValtuilleFernández, E.; Aller-Sanchez, F.; Heras-González, A.; Forensic. Sci. Int. 2018, 292, 167.

263. Zhang, T. L.; Wu, S.; Dong, J.; Wei, J.; Wang, K.; Tang, H.; Yang, X.; Li, H.; J. Anal. At. Spectrom. 2015, 30, 368.

264. Ahamer, C. M.; Eschlbock-Fuchs, S.; Kolmhofer, P. J.; Rossler, R.; Huber, N.; Pedarnig, J. D.; Spectrochim. Acta, Part B 2016, 122, 157.

265. Sun, L.; Yu, H.; Cong, Z.; Xin, Y.; Li, Y.; Qi, L.; Spectrom. Acta, Part B 2015, 112, 40 .

266. Wu, S.; Zhang, T. L.; Tang, H. S.; Wang, K.; Yang, X. F.; Li, H.; Anal. Methods 2015, 7, 2425.

267. Lin, J.; Lin, X.; Guo, L.; Guo, Y.; Tang, Y.; Chu, Y.; Tang, S.; Che, C.; J. Anal. At. Spectrom. 2018, 33,1545.

268. Luo, D.; Liu, Y.; Li, X. Y.; Zhao, Z. Y.; Wang, S. G.; Zhang, Y.; Plasma Sci. Technol. 2018, 20, 075504.

269. Shakeel, H.; Haq, S. U.; Abbas, Q.; Nadeem, A.; Palleschi, V.; Spectrochim. Acta, Part B 2018, 146, 101.

270. He, X.; Chen, B.; Chen, Y.; Li, R.; Wang, F.; J. Anal. At. Spectrom. 2018 , 33, 2203.

271. Ignatyev, I. A.; Thielemans, W.; Vander Beke, B.; Chem. Sus. Chem. 2014, 7, 1579 .

272. Morgan, A. B.; Gilman, J. W.; Fire Mater. 2013, 37, 259.

273. Afonso, J. C.; Rev. Virtual Quim. 2018, 10, Aceito para publicação.

274. Cadore, S.; Matoso, E.; Santos, M. C.; Quim. Nova 2008, 31, 1533.

275. Gerbase, A. E.; Oliveira, C. R.; Quim. Nova 2012, 38, 1486.

276. Henrique, S. S.; Moura, F. P.; Correa, R. S.; Afonso, J. C.; Quim. Nova 2013, 36, 570 .
277. Liu, K.; Tian, D.; Li, C.; Li, Y.; Yang, G.; Ding, Y.; TrAC - Trends Anal. Chem. (2018), doi:10.1016/j.trac.2018.11.025

278. Sattmann, R.; Monch, H.; Krause, H.; Noll, R.; Couris, S.; Hatzipostolou, A.; Mavromanolakis, A.; Fotakis, C.; Larrauri, E.; Miguel, R.; Appl. Spectrosc. 1998, 52, 456.

279. Anzano, J.; Casanova, M. E.; Bermudez, M. S.; Lasheras, R. J.; Polym. Test. 2006, 25, 623.

280. Lasheras, R. J.; Bello-Galvez, C.; Anzano, J.; Polym. Test. 2010, 29 , 1057.

281. Unnikrishnan, V. K.; Choudhari, K. S.; Kulkarni, S. D.; Nayak, R.; Kartha, V. B.; Santhosh, C.; RSC Adv. 2013, 3, 25872.

282. Aquino, F. W. B.; Pereira-Filho, E. R.; Talanta 2015 ,134, 65.

283. Anzano, J.; Bonilla, B.; Montull-Ibor, B.; Casas-Gonzalez, J.; J. Appl. Polym. Sci. 2011, 121, 2710.

284. Banaee, M.; Tavassoli, S. H.; Polym. Test. 2012, 31, 759.

285. Barbier, S.; Perrier, S.; Freyermuth, P.; Perrin, D.; Gallard, B.; Gilon, N.; Spectrochim. Acta, Part B 2013, 88, 167.

286. Grégoire, S.; Boudinet, M.; Pelascini, F.; Surma, F.; Detalle, V.; Holl, Y.; Anal. Bioanal. Chem. 2011, 400, 3331.

287. Costa, V. C.; Aquino, F. W. B.; Paranhos, C. M.; Pereira-Filho, E. R.; Waste Manage. 2017, 70, 212.

288. Lazic, V.; Filella, M.; Turner, A.; J. Anal. At. Spectrom. 2018, 33, 1917. 289. Madariaga, J. M.; Anal. Methods 2015, 7, 4848.

290. Harmon, R. S.; Russo, R. E.; Hark, R. R.; Spectrochim. Acta, Part B 2013, 87, 11.

291. Aramendia, J.; Gomez-Nubla, L.; Castro, K.; Vallejuelo, F. O. G.; Arana, G.; Maguregui, M.; Baonza, V. G.; Medina, J.; Rull, F.; Madariaga. J. M.; TrAC - Trends Anal. Chem. 2018, 98, 36.

292. Botto, A.; Campanella, B.; Legnaioli, S.; Lezzerini, M.; Lorenzetti, G.; Pagnotta, S.; Poggialini, F.; Palleschi, V.; J. Anal. At. Spectrom. (2019), doi:10.1039 / C8JA00319J.

293. Dell'Aglio, M.; Alrifai, R.; Giacomo, A.; Spectrochim. Acta, Part B 2018, 148, 105.

294. Godoy, Q.; Leme, F. O.; Trevisan, L. C.; Pereira-Filho, E. R.; Rufini, I. A.; Santos, D.; Krug, F. J.; Spectrochim. Acta, Part B 2011, 66, 138. 